\title{
Efficiency and Environmental Impacts of Electricity Restructuring on Coal-fired Power Plants*
}

\author{
H. Ron Chan Harrison Fell Ian Lange Shanjun Li ${ }^{\dagger}$
}

\begin{abstract}
We investigate the efficiency and environmental impacts of electricity market restructuring by examining changes in fuel efficiency, cost of coal purchases, and utilization among coal-fired power plants based on a panel data set from 1991 to 2005. Our study focuses exclusively on coal-fired power plants and uses panel data covering several years after implementation of restructuring. The estimation compares how investor-owned (IOs) plants in states with restructuring changed their behavior relative to IOs in states without. Our analysis finds that restructuring led to: (1) a 1.4 percent improvement in fuel efficiency, (2) an 8 percent decrease in unit cost of heat input, and (3) a lower capacity factor even after adjusting for cross-plant generation re-allocation due to cost reductions. The estimates imply that restructuring has led to nearly 15 percent savings in operating expenses and up to 7.5 percent emissions reduction among these plants.
\end{abstract}

Keywords: Electricity Restructuring, Firm Behavior, Emissions

JEL classification: L51, L94, L98, Q48

Running title: Impacts of electricity restructuring

${ }^{*}$ We thank Kathy Baylis, Matthew Chesnes, Dave Evans and seminar participants at Cornell University, University of Colorado-Denver, University of California-Berkeley, University of California-San Diego, University of Maryland, 10th Annual International IO Conference, 14th Annual CU Environmental and Resource Economics Workshop, CESifo Energy and Climate Economics Conference for helpful comments. All errors are our own. This project is partially supported by the Environmental Protection Agency under EPA agreement number PI -83425801-0 and the USDA National Institute of Food and Agriculture, Hatch project NYC-121402. Any opinions, findings, conclusions, or recommendations expressed here are those of the authors and do not necessarily reflect the view of the funding agencies.

${ }^{\dagger}$ Chan is a lecturer (assistant professor) in environmental economics at the University of Manchester, ron.chan@manchester.ac.uk. Fell is an associate professor at the Department of Agricultural and Resource Economics, North Carolina State University, hfell@mines.edu. Lange is an assistant professor at the Division of Economics and Business, Colorado School of Mines, and ilange@mines.edu. Li is an associate professor at the Dyson School of Applied Economics and Management, Cornell University, SL2448@cornell.edu.

(C) 2016. This manuscript version is made available under the Elsevier user license

http://www.elsevier.com/open-access/userlicense/1.0/ 


\section{Introduction}

Introducing competitive markets has been perceived, and generally found empirically, as a way to increase efficiency and productivity across a wide spectrum of industries. ${ }^{1}$ During the 1990s all U.S. states and D.C. held hearings considering the move from regulated electricity generation and transmission system, under which so-called cost-of-service (COS) pricing existed, to more competitive electricity markets. The potential benefits and pitfalls of such restructuring have been well studied (e.g., Laffont and Tirole, 1993), but the basic argument in favor of restructuring is quite simple. COS pricing (a form of cost-plus contracting) provides little incentive for integrated electricity companies to become more efficient, while competitive electricity markets should incentivize firms to lower costs of generating electricity. Though the argument for restructuring appears quite straightforward, relatively few states passed and enacted electricity restructuring laws meant to aid in the formation of these competitive markets. ${ }^{2}$ However, this heterogeneity in electricity market regulations across states, combined with the availability of now several years of data after the implementation of restructuring, presents a suitable setting to empirically analyze the effects of competition on electricity generators. To that end, we analyze the effect of restructuring on fuel efficiency (measured by heat rate, BTUs of fuel input per unit of electricity generated), coal procurement prices, and capacity utilization among coal-fired generating plants using a fifteen year (1991-2005) panel data set. With estimated impacts on firm behavior, we then provide a look at the (unintended) environmental impacts of electricity market restructuring.

This study is not the first effort to empirically estimate the effects of restructuring on generating firms' behavior. The initial wave of articles testing whether plants have improved their performance after restructuring generally do not include, or had very little, data after restructuring was in effect. For example, Douglas (2006) use data on coal-fired plants from 1981-2000, Fabrizio et al. (2007) used data on fossil-fueled plants from 1981-1999, and Zhang (2007) used data on nuclear plants from 1992-1998. These studies find various impacts they attribute to deregulation, though none find evidence of impacts on fuel efficiency directly. ${ }^{3}$

\footnotetext{
${ }^{1}$ For example, see competition impacts on efficiency and productivity in telecommunications from Olley and Pakes (1996), in the concrete industry from Syverson (2004), in natural gas from Davis and Kilian (2011), airlines, railroads.

${ }^{2}$ This is likely due, at least in part, to the restructuring-induced difficulties experienced in the California electricity market in 2001 (Fowlie, 2010).

${ }^{3}$ More specifically, Douglas (2006) finds more efficient plants were dispatched more often when system operators undertook market-oriented reforms, Fabrizio et al. (2007) find that investor-owned plants in states
} 
Much of the literature that includes data after restructuring was implemented has focused on the impact of divestiture. Bushnell and Wolfram (2005), using data from 1997 through 2003 on natural gas and coal plants, find that divested plants and plants that were subject to restructuring but not divested both improved their fuel efficiency by about 2 percent, implying that the change in incentives under restructuring is the main driver of the fuel efficiency improvement. Similarly, Davis and Wolfram (2012) use data on nuclear plant operation from 1970-2009 and find divestiture is associated with a 10 percent increase in operating efficiency, largely driven by a reduction in outages. With respect to fuel purchasing costs for coal and natural gas plants, Cicala (2015) finds in work concurrent, but independent, to ours, a 12 percent reduction in the cost of coal at divested plants but no corresponding reduction in natural gas prices. Efficiency and cost of operation effects of electricity restructuring have also been studied for markets outside the United States, using data from India (Cropper et al. (2011)) and England and Wales (Newbery and Pollitt (1997)) among other places. ${ }^{4}$

Our study differs from these previous works in several key ways. First, we consider only coal-fired generation plants. Similar to those studies mentioned above that only consider nuclear facilities (Zhang (2007) and Davis and Wolfram (2012)), restricting our sample to coal-fired plants limits confounding factors that could arise from the differences across power generation technologies. In addition, there is renewed interest in determining factors influencing coal plants efficiency decisions specifically as improvements in fuel efficiency among coal plants is one of the "four building blocks" the EPA used in determining the emission rates for each state under the recently proposed Clean Power Plan (CPP). ${ }^{5}$ Second, the time span of our data allows us to examine the impacts of restructuring on coal plants with several years of post-restructuring observations. This provides a distinct difference from the data used in Fabrizio et al. (2007), which ended near, or even before, the time when many proposed competitive markets were implemented. This also allows us to assess a variety

that passed some form of restructuring legislation reduced their labor and non-fuel operating expenses, and Zhang (2007) finds an 11 percent reduction in operating costs and 7 percent increase in utilization at nuclear plants when states formally move towards electricity market restructuring. Fabrizio et al. (2007) did specifically test for fuel efficiency improvements among plants in deregulated areas, but found no evidence of this.

\footnotetext{
${ }^{4}$ Beyond the aforementioned studies regarding restructuring-related changes to plant operations, several other studies have examined the possibility of market power in the newly created wholesale electricity markets. (e.g., Wolfram (1999), Borenstein et al. (2002), Mansur (2007, 2008), and Hortaçsu and Puller $(2008))$.

${ }^{5}$ The CPP's targets for the states were determined in part under the assumption that coal plants could achieve a six percent improvement in fuel efficiency.
} 
of treatment start dates and thus more robustly consider possible anticipatory or delayed responses of the regulations. Third, in addition to the efficiency impact as has been done in the literature, we are also interested in the environmental impact from restructuring. This "side" benefit, not well understood in the literature, could be potentially important due to changes in fuel efficiency and shifting of production across plants and could further have implications for calculating baseline emission rates used in the CPP. We examine the impacts of restructuring on three outcomes: heat rate, unit coal cost, and capacity utilization, all of which are factored into the analysis of the environmental impact. Lastly, our study is one of the first studies to examine how restructuring affects fuel (i.e., coal) purchasing costs. COS regulation generally made electricity customers the residual claimant of lower coal prices (through a reduction in the price of electricity) or may have imposed other objectives to plant's purchasing decision, such as excessive risk aversion (Borenstein et al. (2012)). Restructured markets makes the generator the residual claimant and remove other potential objectives, thus altering plants incentives when bargaining with a coal mine. As fuel is the largest part of operating expenses, this change in incentives could imply a big rent transfer from coal mines.

We find approximately a 1.4 percent improvement in fuel efficiency, after restructuring among investor owned plants (IOs) in states that carried out restructuring relative to IOs in states without restructuring. We also find that publicly (municipal, state or federal) or cooperatively owned plants (POs), which often still fall under COS pricing regardless of the state laws on restructuring, show no significant difference in heat rates compared to plants in states without, suggesting that there are no measurable efficiency spillovers from IOs to POs within restructured states. When looking at the restructuring effects on the cost of coal purchases per-unit of heat input, we find that IOs in states with restructured markets had a 6 to 10 percent reduction in per-unit cost of coal purchases compared to IOs purchasing coal with similar attributes in regulated states. No statistical significant effect is found for POs' cost of coal purchases. Further analysis reveals that states which started but stopped restructuring realize very little, if any, of the improved heat rate or reduced cost of coal discussed above. In terms of capacity factors (annual output divided by potential output), our reduced form specification finds that restructuring leads to statistically significant reduction among IOs in restructured states. However, at the same time our analysis shows that capacity factors increase as cost of generation decreases. Given that our heat rate and cost of per-unit coal purchases imply reduced costs per megawatt-hours 
(MWh) for IOs in restructured states, the results imply that restructuring has two opposing effects on capacity factors. Based on our estimated parameters, the combined effect leads to a decrease in capacity factors for IOs in restructured states. ${ }^{6}$ This capacity factor result again has implications for the CPP as an additional building block for a given state's emission rate is an assumed level of coal-to-gas generation switching, which will obviously be affected by the level of capacity utilization of existing coal plants.

Performing some back-of-the-envelope calculations, we find that the estimated improvement in fuel efficiency and reduction in cost of coal purchases imply a $\$ 8$ million average annual cost saving per plant. Using the U.S. Environmental Protection Agency's (EPA) Integrated Planning Model assumptions, this would imply a 14 percent reduction in operating expenditures for the average plant in our sample. The improvement in fuel efficiency and change in capacity factors imply average annual emissions reductions of approximately 2,300, 800, and 235,000 metric tons in $\mathrm{SO}_{2}, \mathrm{NO}_{X}$, and $\mathrm{CO}_{2}$ per plant, respectively, if we assume that reduced generation from coal plants is replaced with natural gas generation. ${ }^{7}$ Applying the marginal damages of $\mathrm{SO}_{2}$ calculated in Muller et al. (2011), the environmental benefit of reduced $\mathrm{SO}_{2}$ emissions from restructuring would be valued at $\$ 5.7$ million per plant per year.

The remainder of the paper is organized as follows. The following subsection provides a brief introduction to the electricity sector and restructuring. Section 2 presents our empirical models and identification strategy. Data are presented in Section 3 and empirical results are in Section 4. In Section 5, we compute the cost savings and environmental impacts of restructuring based on estimates in Section 4. Section 6 concludes.

\section{$1.1 \quad$ Industry Background}

As noted above, U.S. states have traditionally regulated all stages of the electricity industry as it was perceived that the electricity industry was a natural monopoly. Thus, historically public- or investor-owned firms acted as regulated and vertically integrated monopolies,

\footnotetext{
${ }^{6}$ This result is in contrast to the strong evidence of increased capacity factor for nuclear plants in restructured states found in Zhang (2007) and Davis and Wolfram (2012). This discrepancy could be explained by the relatively flat electricity demand during the data period; if nuclear plants run more often than our finding on coal-fired power plants should not be viewed as being in contradiction with theirs.

${ }^{7}$ Emissions savings are larger if we assume that nuclear generation replaces the reduced generation in coal, with average annual emissions reductions per plant for $\mathrm{SO}_{2}, \mathrm{NO}_{X}$, and $\mathrm{CO}_{2}$ of approximately 2,300, 1000 , and 392,000 metric tons, respectively.
} 
controlling the generation, transmission, distribution, and retail sectors of the industry. Individual states set the parameters of the regulation with all having some form of COS regulation. Under COS regulation, firms were compensated for operating expenses and a rate of return was allowed for capital costs, subject to state regulators' approval of the firms' transactions. Such a form of cost-plus contracting has often come under criticism for providing poor incentives for efficient investment and operation and prompted moves toward restructuring. ${ }^{8}$

The federal government encouraged the move to wholesale electricity market competition. In particular, the Energy Policy Act of 1992 opened the door for electricity market restructuring by putting a framework in place that allowed non-discriminatory access to the generation grid, giving rise to greater access for generators unaffiliated with large integrated utilities. This federal action, combined with desire for more efficient generation prompted states to investigate the impacts of restructuring their electricity market. Table 1 lists the states and timing of the formal hearings, restructuring legislation passage, and official repeal or suspension of restructuring efforts. The forms of the legislations varied slightly across the states that enacted restructuring. However, the overarching theme of restructuring legislation is a separation between the generation and transmission/distribution assets of what had been vertically integrated IO utilities and a push to create competitive wholesale electricity markets. ${ }^{9}$ Additionally, restructured states enacted changes to the retail side of the electricity market by allowing retail choice, although this was phased in over time in most places and was accompanied by temporary rate freezes in some states to prevent price discrimination by retail electricity providers. The combined changes to wholesale and retail electricity markets in restructured states clearly leave the generating plants in these states to operate in a more competitive environment than those in regulated states. It is the impact of operating in an increased competitive environment that is analyzed here.

\footnotetext{
${ }^{8}$ Realizing the COS regulation could misalign efficiency incentives, some states also introduced regulations to encourage efficiency within the COS framework. See Knittel (2002) for an analysis of these alternative measures.

${ }^{9}$ For instance, Connecticut required all previously vertically integrated utilities to divest all generation assets, Rhode Island required generation divestiture but allowed transfers to affiliated companies, and Texas did not require explicit divestitures but did require an unbundling of the generation, transmission and distribution, and retail provider functions of the utilities. Regardless of the prescribed divestiture plan, many utilities in states that passed and enacted restructuring legislation did divest all or some of their generation assets to become more retail-sales focused companies. This voluntary divesting of generation assets also occurred in a few instances for utilities in regulated states.
} 


\section{Empirical Model}

The first goal of the paper is to identify the impacts of electricity market restructuring on the behavior of coal-fired power plants in three important dimensions: fuel efficiency, coal price, and capacity utilization. We use heat rate, defined as the Btus per MWh, as our measure of efficiency as is standard in the electricity industry. In examining coal price, we focus on the unit cost of coal procurement, defined in terms of cost per unit of heat purchased (real dollars per million Btus). Finally, our measure of capacity utilization is the industry standard capacity factor, defined as annual net generation in MWh's divided by the plants possible generation (capacity times number of hours in the year).

Our empirical research design is a difference-in-differences (DD) estimation. The impacts of restructuring are identified through: (1) the fact that some states never undertook restructuring (henceforth, non-restructured states); and (2) the fact that restructuring started in different years in restructured states. Therefore, we define our control group to include the coal-fired power plants in non-restructured states and the treatment group to include coalfired power plants in restructured states, bearing in mind that the temporal variation in treatment adds to the geographic variation for identification of the impacts.

Given this research design our primary estimation equation can be written generally as a linear two-way fixed effect model:

$$
y_{i t}=\alpha \mathrm{RST}_{i t} \mathrm{IO}_{i t}+\beta \mathrm{RST}_{i t} \mathrm{PO}_{i t}+\mathrm{X}_{i t} \gamma+\delta_{i}+\eta_{t} \mathrm{IO}_{i t}+\xi_{t} \mathrm{PO}_{i t}+\mathrm{u}_{i t} .
$$

In (1), the subscript $i$ defines the plant and $t$ defines the year. The dependent variable $y_{i t}$ is either the $\log$ of heat rate $\left(H R_{i t}\right)$, log of coal procurement costs $\left(\right.$ UnitHeatCost $\left._{i t}\right)$, or the following monotonic transformation of capacity factor $\left(\right.$ CapFactor $\left._{i t}\right): \log \left(\frac{\text { CapFactor }_{i t}}{1-\text { CapFactor }_{i t}}\right) \cdot{ }^{10}$ $\mathrm{RST}_{i t}$ is a dummy variable equal to one if the state where plant $i$ is located is a restructured state and started the restructuring process during or before year $t$ and zero otherwise. ${ }^{11} \mathrm{IO}_{i t}$ is a dummy variable equal to one if plant $i$ is an $\mathrm{IO}$ plant at year $t$. $\mathrm{PO}_{i t}$ is equal to one if

\footnotetext{
${ }^{10}$ The capacity factor variable is generally between zero and one and thus simple log transformation would result in a variable that is generally always negative. The transformation used here is defined to have support on both sides of zero. This transformation also allows us to capture the heterogeneous impact of increasing capacity when the utilization was $50 \%$ versus when it was $90 \%$, where the cost is much higher in the latter case.

${ }^{11}$ In the baseline model, we consider the restructuring process starts with the formal hearing by state legislators as in Fabrizio et al. (2007). This specification allows behavioral changes by power plants in anticipation of restructuring.
} 
plant $i$ at year $t$ is a PO plant and zero otherwise. We allow for an IO-specific treatment effect $(\alpha)$ and PO-specific treatment effect $(\beta)$ because many POs within regulated states remain primarily vertically integrated utilities that operate under some form of a traditional cost of service regulation. ${ }^{12}$ Time varying controls are included in the vector $\mathrm{X}_{i t}$, where different sets of controls are used with different dependent variables. The plant-level fixed effects are given as $\delta_{i}$ and separate time fixed effects are given for IO's $\left(\eta_{t}\right)$ and PO's $\left(\xi_{t}\right)$ to control for group-specific time trends. The remaining term, $\mathrm{u}_{i t}$ picks up the idiosyncratic error term.

For the specification with $\log \left(H R_{i t}\right)$ as the dependent variable, the control variables include a set of time-varying plant characteristics and regulatory environment such as, if the plant has scrubber installed, if the plant participates in the first phase of the $\mathrm{SO}_{2}$ permit trading program, if other incentive regulations exist in a state, whether a plant was divested voluntarily in states without restructuring, whether the state was part of a $\mathrm{NO}_{X}$ permit trading program, the logarithm of generation capacity, and the logarithm of output level. ${ }^{13}$ Given the log transformations, the inclusion of both capacity and the output level variables allows the heat rate to be affected by the size of the plant as well as the utilization rate, both of which are likely to impact heat rates given engineering relationships between size, usage rates and efficiency.

The $\mathrm{X}_{i t}$ vector for the specification that uses $\log \left(\right.$ UnitHeatCost $\left._{i t}\right)$ as the dependent variable contains several different variables than those for the heat rate specification. In particular, to control for coal types on unit heat cost, we include sulfur content and ash content (per million Btus) as well as their interactions with dummy variables for $\mathrm{SO}_{2}$ permit trading and scrubber installation. $\mathrm{X}_{i t}$ also includes the logarithm of coal quantity purchased (in million Btus) to control for possible volume discount. In addition, the vector of explanatory variables contains the share of coal purchased from the spot market. ${ }^{14}$ The additional variables in $\mathrm{X}_{i t}$ also appear in the heat rate equation above: a dummy variable for scrubber,

\footnotetext{
${ }^{12}$ For example, the Gibbons Creek power plant in Texas, which is a restructured state, is operated by the Texas Municipal Power Agency (TMPA). TMPA operates as a non-profit municipal utility and is wholly owned by the cities it serves: Bryan, Denton, Garland and Greenville Texas.

${ }^{13}$ As discussed above, some divestiture was forced as part of the restructuring legislation and some was voluntary. Note also, some divestitures occurred in states that did not enact restructuring. We do not distinguish among the methods for divestiture, but rather simply control for this as in other studies.

${ }^{14}$ Most power plants purchase coal from both the spot market (spot coal) and long-term contracts (contract coal). Prices of contract coal are generally higher and with higher sulfur content than spot coal based on the data. The spot share variable is used to control for the difference in the price risk from these two purchasing channels.
} 
a dummy variable for participation in the first phase of the $\mathrm{SO}_{2}$ permit trading program, and generation capacity. Given these set of controls, our specification treats the quantity purchased as a characteristics of the goods in a hedonic framework, thus equation should not be viewed as a demand equation for coal.

For the capacity factor specification, we aim to understand how restructuring affected the utilization of coal-fired power plants by using a reduced form specification. To examine how they are affected by restructuring, ideally wholesale electricity prices (or a representative wholesale prices for plants in vertically integrated utilities that do not operate in a competitive wholesale power market) at which power plants are paid would be included in the set of control variables. To proxy for a representative wholesale electricity prices, we use capacity factors at the state level for two types of plants: natural gas power plants and fuel oil plants. ${ }^{15}$ Generators that primarily use these fuels are generally peak load generators and only turned on during high demand periods due to their relatively high marginal costs and, thus, their utiliztion rates are likely positively correlated with higher wholesale prices. ${ }^{16}$ The capacity factor equation should also account for the cost of generation. Since fuel cost account for the bulk of a plants operating costs (Fabrizio et al., 2007; Linn et al., 2014), we include the cost of heat input (from coal) per kilowatt-hour (KWh). In addition, we include other plant and regulatory variables in $\mathrm{X}_{i t}$ such as if the plant has scrubber installed, if the plant participates in the first phase of $\mathrm{SO}_{2}$ permit trading program, generation capacity, incentive regulation and voluntary divestiture in regulated states.

\subsection{Identification}

There are a number of concerns in estimating restructuring impacts based on the empirical models outlined above that should be addressed. First, there are a set of assumptions that must be met for our DD framework to be able to identify the restructuring treatment effect.

\footnotetext{
${ }^{15}$ Regional wholesale day-ahead market prices are generally available for those regions with functioning markets. For other regulated regions, FERC provides "system- $\lambda$ 's", effectively a measure of the cost of a marginal increase in generation for the system. However, in many instances market prices and system- $\lambda$ 's are not directly comparable (i.e., prices are not always equal to the cost of a marginal increase in generation in all hours). We therefore use proxies for prices.

${ }^{16} \mathrm{We}$ also experiment with adding retail prices for industrial customers, which tend to be more contemporaneously tied to current wholesale-market/production-cost conditions, in the equation and obtain very similar results. In addition, recently low natural gas prices in the U.S. have allowed some natural gas plants to achieve lower marginal costs of production than some coal plants. However, over the period examined in this paper, natural gas prices were relatively high, so it is unlikely that high natural gas plant capacity factors are driven by relative prices over our sample.
} 
The second concern arises from the potential endogeneity of some of the control variables used across the three dependent variable specifications. Finally, issues related to plant exit may create selection bias if less efficient plants are more likely to exit. We discuss these three issues in turn.

The validity of a DD framework in identifying treatment effects generally rests on three assumptions: exogeneity of the treatment assignment, common pre-treatment trends in the dependent variable across the control and treatment groups, and that the treatment does not affect the outcomes of the control group (the Stable Unit Treatment Value Assumption). The exogeneity of treatment assumption could be violated in this context if states choose to initiate the restructuring process in response to unobserved time-varying factors that affect the three dependent variables of interest at coal-fired plants. We believe that this violation is unlikely to happen: the driving force behind the restructuring that started in California and states in the Northeast was high historical average costs from uneconomic investments (primarily in nuclear plants) and the political affiliation of the legislature (White, 1996). Thus, the impetus and timing of the legislative process is likely determined by political reasons and historic elements of COS regulation rather than contemporaneous operational conditional in coal-fired power plants.

To explore the possibility for differing underlying trends in the data across the control and treatment groups we take advantage of the several years of data available before restructuring to test for differences in pre-treatment trends. More specifically we estimate a modified version of equation (1) where we exclude the first two terms but include separate year dummies for the treatment and control groups. Results of the time fixed effects for the treated group are shown in Figures 1 - 3. These plots generally do not show pre-existing differences in time trend. ${ }^{17}$ Finally, we argue that the restructuring efforts of some states is unlikely to affect the behavior of the control plants in the traditionally regulated states because the control plants remained under their traditional COS regulation which served to protect these plants from outside competition. As such, if the introduction of competition is

\footnotetext{
${ }^{17}$ These plots use 1991 as the base year and are relative to the IO's in the control group. Thus, a statistically insignificant estimate means the treatment is not materially different from IO's in the control group for the given year. Recall also that restructuring hearings, the timing of which is the beginning of our treatment period in our base specifications, began as early as 1994. Thus we would expect to see year dummy parameters in these figures that are not statitically different for at least years prior to 1994. This can be shown for all dependent variable specifications. Among the 146 plants in the treatment group (i.e., those eventually went through the restructuring process), 61 of them started have started the restructuring process in 1994, 93 in 1995 and 125 in 1996.
} 
the primary driver of the estimated changes, protection from that competition should shield control plants from any spillover effects. ${ }^{18}$

The second empirical challenge arises from the potential endogeneity in some of the explanatory variables in $\mathrm{X}_{i t}$ in each of the three equations. For example, the specification with log of heat rate as the dependent variable includes plant output (electricity generation) as one of the explanatory variables. Since the output level and heat rate at a plant are determined at the same time during the course of plant operation, we face an endogeneity issue due to simultaneity. We employ a series of regional demand measures and demand shifters including state-level total electricity consumption, gross state product, and housing starts to construct instrumental variables (IVs) for plant output. Similar IV's were also used in Fabrizio et al. (2007). The IV's seem reasonable as we would expect varying demand conditions to impact a plant's ability to supply power, but unobservables affecting a plant's fuel efficiency are unlikely to be correlated with broader demand conditions. We also interact the electricity consumption, gross state product, and housing starts variables with state-level share of coal plant capacity (over total generation capacity in the state) to account for the possibility that responses to demand conditions at a plant may vary depending on how reliant the state is on coal as a baseload provider. In total, with the interaction terms, we have six instruments as the full set of instruments.

A simultaneity issue also likely exists in the hedonic price equation which relates the per-unit-heat cost of coal to it attributes. Two of the explanatory variables from this specification, total coal purchased and the share of coal purchased from the spot market, are likely simultaneously determined with the coal price. That is, the average price can be affected by volume discount and the pricing risk of the spot market (versus the contract), plants' coal purchase decisions including quantity and procurement channels are partly determined by prices. To instrument for these two variables, we use the same set of instrumental variables discussed above. These instruments, reflecting state-level electricity demand conditions, should be correlated with total quantity of coal purchased and the spot share (e.g., as demand increases plants are likely to need to purchase more total and likely more from the spot market to cover extra generation) but not correlated with the error term in the price

\footnotetext{
${ }^{18}$ The fact that restructured plants may compete with regulated plants in wholesale markets organized by a regional transmission organziation (RTO) may lead to changes in behavior of those regulated plants. In estimations not shown here but available by request, the treatment effect is statistically and economically unchanged by an inclusion of a dummy variable that indicates a regulated plant that is part of wholesale market organized by an RTO.
} 
equation such as unobserved coal attributes or purchasing contract characteristics.

The capacity factor specification also exhibits the simultaneity issue with the included explanatory variables that captures the cost per unit of generation because a high unit cost of generation could reduce capacity factor while a high capacity factor could alter fuel efficiency and hence affect heat input cost. We use the aggregate variables for demand condition as IV's for generation costs as they are unlikely to be correlated with plant-level idiosyncratic shocks but could affect coal prices (and thus fuel costs per MWh). Similarly, as wholesale prices are endogenous due to simultaneity, so may be the proxies for wholesale electricity prices, contemporaneous state-level capacity factors for natural gas plants and fuel oil plants, used in our capacity factor specification. We instrument for these two variables with the aggregate demand condition variables as well to control for potential correlation between them and idiosyncratic plant supply shocks.

The final empirical challenge lies in the fact that power plants may exit the sample due to retirement or missing data. If plant exit is not random, it could lead to selection bias in coefficient estimates. For example, if competition leads to increased probability of exit among inefficient plants, the effect of restructuring on plant efficiency could be overestimated based on observed data. Although previous literature have shown that sample selection could introduce serious bias in other context (Olley and Pakes, 1996), this is not the case in the electricity industry, largely because the small number of exits among power plants. ${ }^{19}$ To check if sample selection could introduce serious bias, we follow their strategy by estimating set of equations in (1) using a balanced sample of power plants. Similar to their finding, the results from this smaller sample are all very close to those from the full sample.

\section{Data}

Our data set includes annual plant-level information from 1991 to 2005 gathered from various survey forms from U.S. Energy Information Administration (EIA) and EPA Clean Air Markets Database. We identified coal-fired plants as being plants where at least one boiler is fueled primarily by coal using classification stated in the EIA-860 form. To reduce possible confounding factors that may be present for plants that have ample capacity to switch

\footnotetext{
${ }^{19}$ The data show seven boilers which stopped reporting at some point after restructuring took place. The plant's average fuel efficiency was not statistically different after the retirements. Fabrizio et al. (2007) note a similar feature in their data.
} 
generation fuel between coal and other fuels, we restrict our sample to those identified as primarily coal plants. However, those plants that list coal as their primary fuel may still burn some other fuels. The burning of other fuels in these plants is primarily to heat the coal boilers and is not for direct generation so we ignore the consumption of these other fuels. The EIA-860 form also provides information on plants' nameplate capacity, which we use to define the capacity variable and in the construction of the capacity factor variable, as well as the plant location (state) and the year the plant came on (from which we derive plant age). We acquire additional plant information from EIA-861, which gives us information on ownership type (IO or PO) on the firms and their respective plants. ${ }^{20}$ Controls for whether a plant is required to participate (or join voluntarily from the Opt-in program) in the Acid Rain Program (ARP) and NOx Budget Trading Program (NBP), using data from the EPA Clean Air Markets database, are used as independent variables in our regression analyses.

We derived plant-level coal input use (in MMBtu's) and net generation (generation net of power used to create the generation given in MWh's) using the EIA-759 form, the EIA-767 form and the EIA-906/920 form. The data is extracted from EIA-759 and EIA-906/920, the successor form of the EIA-759 starting in 2001, both of which contain plant-level net generation by fuel type. ${ }^{21}$ The EIA-767 form gives monthly boiler-level fuel use by fuel type and we aggregate to derive the coal input use variable as the sum of MMBtu's of coal burned at the given plant. ${ }^{22}$ The fuel-use variable is used along with the net generation variable to derive the heat rate variable (fuel-use/net generation).

The EIA-767 form also contains plant design information of use to our study. Specifically, it identifies whether or not a plant $i$ in year $t$ has a "scrubber" installed, which is used to effectively remove $\mathrm{SO}_{2}$ emissions. Scrubber $i t$ takes the value of 1 if at least one boiler has a scrubber installed at time $t$ and is zero otherwise. ${ }^{23}$ We include this information in the

\footnotetext{
${ }^{20}$ The EIA-860 form provides information on the name of the actual plant owner. In robustness checks we control for issues such as whether or not the plant has multiple owners, which gives us a control for possible cross-plant information sharing. These controls did not lead to materially different estimates than what is presented. We also checked if any plants in regulated regions were owned by firms that also owned plants in deregulated regions. For our sample, only 0.5 percent of plants are owned by firms that own plants in both regulated and deregulated regions. Thus, there it is unlikely that ownership issues will confound our treatment effect.

${ }^{21}$ EIA originally requires only utilities to file EIA-759 form. Following the first wave of divestitures in 1999, the divested units are required to file EIA-906 instead of EIA-759 which contains the same elements as in EIA-759. We used both forms to determine their net generation depending on their divestiture status.

${ }^{22}$ The EIA-767 form also gives net generation information by boiler but it appears that the EIA-906/920 data, which also collects monthly fuel use and net generation data, is more complete for 2001 - 2005.

${ }^{23}$ We also used a percent of plant capacity scrubbed variable in analyses not shown here. Results are
} 
dummy variable Scrubber $_{i t}$ as it affects what types of coal a plant may purchase and possibly affects operational efficiency.

The FERC-423 form collects monthly reports on the fuel purchases, including the heat, ash, and sulfur content of the purchased coal, the origin of the fuel as well as the purchase cost (inclusive of delivery), for each plant-level transaction made by coal-fired power plants. Given that our other data are of annual frequency, we develop a yearly average measure of the relevant variables in the 423 form. ${ }^{24}$ We compute a weighted average of the ash and sulfur content using heat content of each transaction as the weight. Analogously, we compute the total cost of coal purchases by summing across all fuel cost multiplied by the respective heat content. Annual per-unit heat prices are formed by dividing total annual fuel costs by total annual heat content. The 423 form also records whether these transactions are done in a spot market or they are contract deliveries. EIA defines a spot purchase as a single shipment of fuel or volumes of fuel purchased for delivery within one year. We compute the share of the spot coal purchases made by each plant, defined as the ratio of heat content of all spot coal purchases to the total heat content of all coal purchases, since it will certainly affect the total cost of coal due to differences in the pricing for spot and contract coal.

A concern of using the FERC-423 data is that divested plants no longer have to file the FERC-423 to report their monthly fuel procurement, however IO plants in restructured states still do report, which leads to a drop of the observations. ${ }^{25}$ We checked the trends of unit heat cost for those that remain and those that are no longer in our sample. The plot shows that both the trends and levels are not statistically different for the two groups, allaying some of the concerns over the threat to our identification.

The construction of the restructuring dummy variable $\mathrm{RST}_{i t}$ is defined using the year when hearings on restructuring begin, following the definition used in Fabrizio et al. (2007). However, unlike Fabrizio et al. (2007), we only turn on the restructuring dummy (set the dummy equal to one) for plants that are in states where restructuring actually took place. That is, we acknowledge that there may have been early actions taken by plants who expected restructuring, but we account for the possibility that firms may have known the likelihood

identical in sign and significance to those in Tables 3 and 4 and are available by request.

${ }^{24}$ In the Appendix, we estimate our heat rate equation using observations reported at the monthly level for robustness check.

${ }^{25}$ The FERC-423 data that we use was downloaded in 2006. The data available online has since been altered and now reports coal procurement data for an even more restricted set of plants. From 2002 the divested plants have to file EIA-423 but the delivery cost is not released to the public. 
of actually deregulating and responded accordingly. For the dummy variable LawPass ${ }_{i t}$, we use the date at which the law passed based on the state-level information provided on the EIA website (www.eia.gov/cneaf/electricity/page/restructuring/restructure_elec.html). In robustness checks we alter the timing of the restructuring effect to more thoroughly examine when restructuring began to impact operation.

Following Fabrizio et al. (2007), we only allow plants that have at least three years of

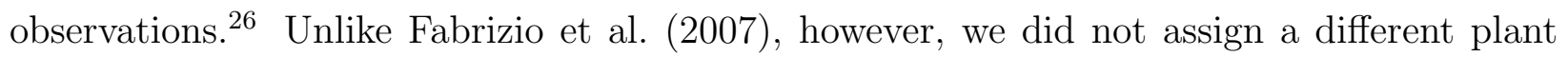
code for plants with a significant change in capacity, defined as either 15 percent or a $40 \mathrm{MW}$ change to allow a different plant fixed effects for the plant before and after the capacity change in their paper. A change of this magnitude occurred for $16 \%$ of the plants in our sample; $35 \%$ of plants have a capacity increase regardless of magnitude. Results are quantitatively similar if the Fabrizio et al. (2007) method of capacity change is utilized. We postulate that the efficiency gain (as measured in heat rate) due to restructuring can possibly come from the generator installations - by treating these plants using the same plant dummy, we are attributing the efficiency gain (by comparing the deregulated IOs to the control) to the restructuring.

Table 2 provides summary statistics on the key variables used in our analysis. The estimation sample contains 418 plants, 310 of which are IOs and 108 that are POs. 122 of the 310 IO plants and 23 of the 103 PO plants are part of the treatment. We compare key variables by treatment group and control group, as well as by the timing of restructuring. The treatment group is defined as the set of investor-owned plants in restructured states while the control group consists of all other plants. ${ }^{27}$ It does not appear that there is a significant change in the heat rate for both groups - though there is a slight decrease (i.e. efficiency improvement) for the deregulated IOs. For both groups, the coal price decreases due to a decreasing trend of coal prices (Bonskowski, 1999); yet the decrease is slightly larger for the deregulated IOs. The increase in capacity factor in the control group is larger than the one observed in the treatment group.

\footnotetext{
${ }^{26}$ We have dropped observations with operating heat rate below 5,000 or above 25,000 MMBtu per kWh, capacity factor below $5 \%$ or above $99 \%$, mean capacity factor below $10 \%$ or above $98 \%$.

${ }^{27}$ As stated in the econometric specifications in Section 2, we control for possible separate effects for POs in restructured states. We group the two here for exposition purposes only.
} 


\section{Estimation Results}

\subsection{Plant fuel efficiency}

Table 3 provides estimation results for equation (1) that explores the relationship between restructuring and heat rate. All standard errors are clustered at the plant level to allow for serial correlation in the error term and all include plant and year fixed effects, with yearly fixed effects differing across PO and IO's. The first column is from an OLS estimation. The second column, the benchmark specification, is from GMM with the Log(output) variable instrumented using the IV's discussed above. The third and fourth columns utilize the GMM-IV model from column two with a balanced panel sample and an IOs only sample, respectively.

The results suggest that restructuring is associated with 1.4 percent reduction in heat rate (i.e., an improvement in efficiency) for IOs plants when treated with restructuring. This effect is consistent across all of the columns. ${ }^{28}$ While we do not have statistically significant effects for POs, the point estimates for POs in restructured states is similar to that for IOs. ${ }^{29}$ Finally, many of the remaining parameters associated with other control variables have signs as expected, with the exception of those on "Scrubber", but are largely statistically insignficant. ${ }^{30}$

To further examine the robustness of our results, we consider several other alternative specifications given in Table 5. All robustness results are estimated using a GMM-IV approach with time and plant fixed effects unless noted otherwise. The first column, "State Cluster", show the results of the benchmark with state-level clustered standard errors (as opposed to plant-level clusters). The sign and significance of our restructuring variables are

\footnotetext{
${ }^{28}$ Given that the OLS and GMM results are similar, we conducted a Hausman-Wu test to determine whether treat $\log$ (output) is as an exogenous regressor. The result of this test is that we fail to reject the null that that $\log$ (output) is exogenous. Given that previous literature has instrumented for $(\log )$ output, we continue to show both the OLS and GMM results.

${ }^{29}$ This "noisy zero" results, the standard errors are more than twice as big as the RST*IO, appears to be driven by the plants in Texas. Dropping Texas from the analysis gives us essentially the same estimate on all parameters except for that on RST*PO, which drops in magnitude to effectively zero.

${ }^{30}$ It takes energy to run the scrubber, so one might expect that the inclusion of a scrubber would lower a plant's net generation and thus increase their heat rate, all other things remaining constant. However, having a scrubber effectively guarantees compliance with $\mathrm{SO}_{2}$ regulations. With compliance assured, the plant may be able to operate with fewer starts and stops or without having to divert funds away from other efficiency improving activities in order to pay for $\mathrm{SO}_{2}$ permits. These features then may allow plants with a scrubber to appear to be as efficient as those without scrubbers.
} 
unchanged. The second and third specifications, remove the states which never actually restructured or repealed their restructuring from the treatment group. For these specifications, the RST*IO variables is one for states (after the date of their hearings) that have not repealed their restructuring legislation and have competitive wholesale markets. $\mathrm{RST}_{1}{ }^{*} \mathrm{IO}$ equals one (after the date of their hearings) for states that passed restructuring legislation, but then repealed their legislation. This parameter will test whether considering restructuring has an impact on plant's performance. The parameter $\mathrm{RST}_{2}{ }^{*} \mathrm{IO}$ equals one (after the date of their hearing) for states which passed restructuring legislation but returns to zero when the restructuring legislation is repealed.

In the second specification, column 2, the coefficient on RST*IO is slightly larger than the in column 2 of Table 3 (-0.016 vs -0.014), which is not surprising because here the RST*IO group loses plants from states that repealed or suspended restructuring) and statistically significant at the 5 percent level while the $\mathrm{RST}_{1} * \mathrm{IO}$ coefficient is much smaller $(-0.006$ vs -0.014) and not statistically different than zero. In column $3, \mathrm{RST}^{*} \mathrm{IO}$ is the same as column 2 and the $\mathrm{RST}_{2}{ }^{*} \mathrm{IO}$ is smaller (-0.009 vs -0.014) and statistically signficant at the $10 \%$ level. These two results reveal that starting then stopping the restructuring process does not provide the same impacts as actually restructuring electricity markets. The fourth column, "LawPass", uses the date the restructuring law passed as the time the RST dummies turns to one instead of the hearing date. The restructuring effect on fuel efficiency for this specification is essentially the same to the other specifications presented for this model. The final specification considered in Table 5, "East Only", drops all plants west of the Mississippi River in an effort to improve the control group. More specifically, there may be geographic differences that lead to changes in plant behavior that is unrelated to restructuring (the biggest coal basin in the West, rail service competition varies over space) and this may make plants in the Western U.S. poor controls for plants in the predominantly restructured Northeast U.S. Results are essentially the same as in the geographically more broadly defined specifications thus it is unlikely our results are driven by geographic differences.

In the appendix, we also include several more specifications specifically for the heat rate model in Table A.1. First, we estimate the model using monthly data. Results from the monthly-data model lead to similar restructuring effects as those shown using the annual data. Also, we aggregate our instruments at the NERC region level as the proxies for demand side variables might be relevant at a broad electricity market level, and the point estimates are very similar. Next, to more directly compared our results to Fabrizio et al. (2007), which 
did not find a restructuring effect, we reduce our sample to the same years that they use, 1991 - 1999. Here we find a statistically insignificant restructuring effect on heat rates. ${ }^{31}$

\subsection{Coal Purchases}

We next consider the effect of restructuring on the cost of coal purchased. It is important to recall that coal is not a homogeneous product, but rather has several key product attributes, including contracting duration, that affect price. Controlling for these attributes, we can determine if restructuring has had any impact on coal purchase costs. Our a priori expectations is that restructuring should lower coal purchasing costs as increasing competition should increase the incentive of plants to lower production costs, of which fuel costs are a signficant portion.

Table 4 reports results from four regressions based on equation (1). The specification breakdowns are similar to those in Table 3. The first column is an OLS estimation with plant fixed effects. The second column, the benchmark specification, is from a GMM model with the Log(BTUs Purchased) and spot share variable is instrumented using instruments discussed above. The third and fourth columns utilize the GMM-IV model from column two with a balanced panel sample and an IOs only sample, respectively.

While results from the simple OLS estimation show no statistically significant restructuring effect, the coefficient estimate on the RST*IO dummy in column 2 suggests that, in line with a priori expectations, restructuring reduces the unit cost of coal by 8.0 percent. This highlights the importance of accounting for the endogeneity in quantities purchased and spot market shares. ${ }^{32}$ The balanced panel results and those comparing only IO's similarly show significant and similarly sized restructuring effects for IOs. Additionally, across all columns the effect of restructuring on POs is consistently insignficant.

With respect to the remaining parameters, we find that the coefficients on Log(BTUs Purchased) and spot share are as expected when using IVs - buying large quantities elicits a

\footnotetext{
${ }^{31}$ Note that we continue to use the restructuring dummy that remains zero for those plants in states that passed, but then did not implement their restructuring rules. That is slightly different from the treatment assignment used in Fabrizio et al. (2007). To even more directly compare our results to theirs, we also used ran regressions using the treatment assignment variable of Fabrizio et al. (2007). The results again show a statistically insignificant restructuring effect.

${ }^{32}$ Indeed, one can see that our specifications that instrument for $\log$ (BTUs Purchased) and spot share flips the sign of the parameters associated with these variables, further emphasizing the endogeneity issue in this specification.
} 
bulk discount and buying more from the spot is done so at a premium. The parameters on ash and sulfur content are somewhat unexpected, as both are positive and the ash content coefficients are significant. However, the ash and sulfur content are negatively correlated with volatile matter and moisture, both of which are not controlled for directly here and have been found to decrease the value of coal (Bellas and Lange, 2007). In addition, the parameter on sulfur content when interacted with participation in the $\mathrm{SO}_{2}$ trading program is negative, suggesting that when a plant's $\mathrm{SO}_{2}$ emissions are regulated more sulfur in the coal reduces the coal cost. Additionally, if the parameter on sulfur interacted with a scrubber is positive which is as expected - if a plant has a scrubber they can easily comply with any $\mathrm{SO}_{2}$ regulation so sulfur content is again going to appear to increase the price of coal due to it's correlation with unaccounted-for positive attributes of coal. ${ }^{33}$ Finally, the parameters on capacity suggest that larger plants may be able to get coal at lower prices, but this size effect has diminishing returns.

As with the heat rate specifications, we perform a set of similar additional robustness checks, the results of which are presented in the bottom panel of Table 5. Again clustering at the state level leads to essentially the same outcome for the restructuring effect as in the benchmark specification. When the states in the $\mathrm{RST}_{1} * \mathrm{IO}$ group (same as discussed above) are seperated from the RST*IO group, we find a slightly higher coefficient on the RST*IO parameter (-9.1 vs -8.0) and that the states that started but stopped restructuring $\left(\mathrm{RST}_{1} * \mathrm{IO}\right.$ coefficient) have no statistical change in their unit heat cost. Additionally, the $\mathrm{RST}_{2} * \mathrm{IO}$ coefficent is not statistically different than zero while the RST*IO coefficient is -9.2 and statistically different than zero. These results, again, support the view that starting and stopping restructuring do not provide the changes to plant performance that come from fully restructuring. The impact of stopping restructuring can be larger for unit heat cost due to the unwinding long term contracts. For plants in states that looked to be headed toward restructuring but did not go through with it, there may not have been sufficient time between restructuring hearings and the realization restructuring was not going to occur for plants to significantly change their contracting positions. For the "LawPass" specification, we find the cost-saving effect from restructuring is even larger than those specifications using

\footnotetext{
${ }^{33}$ As Cicala (2015) discusses, regulated plants were more likely to install scrubbers than deregulated plants. This may lead one to have concerns of a collinearity problem between the variables including the scrubber dummy and the deregulation treatment dummy. However, in our sample roughly 20 percent of all plants with a scrubber installed are IO plants in deregulated regions. Therefore, there appears to be enough variation in scrubber installation to separately identify effects of deregulation and scrubber installation on coal purchasing costs.
} 
that turn on the restructuring dummy when state begins to have hearings on restructuring (-12.7 compared to -8.0). This result is consistent with the unwinding of long term contracts. Finally, for the "East Only" specification, the cost-saving effect of restructuring is smaller in magnitude than for our main specification (-5.4 vs -8.0) but still statistically different than zero. This may be expected since the eastern plants may not have as many opportunities to switch coal suppliers as western and midwestern plants, which could lower the cost-saving abilities of plants in restructured eastern states.

\subsection{Capacity Factor}

Finally, we estimate the effect of restructuring on plant-level capacity factors. Different from the previous two equations, we specify the treatment to begin when the restructuring laws was passed in the corresponding state because until the various restructuring laws went into effect, plants were still traditionally regulated and thus many of the possible capacityfactor altering incentives may not have taken effect. The restructuring dummy is defined as LawPass $_{i t}$ which is equal to one once the restructuring law was passed in the state.

The a priori expected signs of the parameters associated with the restructuring dummies are less apparent. For example, recent studies such as Zhang (2007) and Davis and Wolfram (2012) have found that restructuring, as well as ownership consolidation, has lead to increased capacity factors among U.S. nuclear facilities. This makes intuitive sense as one might expect that competition would force generators to more fully utilize their existing capital. On the other hand, infra-marginal coal-fired generators in wholesale electricity markets may have incentive to reduce production in order to force higher-cost generators on to the margin, thus reaping the benefits of higher market clearing prices. ${ }^{34}$ Evidence of such behavior has been found in several studies (e.g. Wolfram, 1999; Hortaçsu and Puller, 2008; Mansur, 2008). In addition, less efficient plants in wholesale electricity markets may more often get under-bid and thus will be more frequently forced out of the market. While our reduced form estimation strategy does not allow us to identify individual impacts of these, or other, possible restructuring-induced mechanisms, our estimation does provide an overall average effect.

\footnotetext{
${ }^{34}$ Note that unlike nuclear plants that tend to run at constant rates near capacity when operating, coal plants are capable of some degree of "on-load cycling" (changing operational capacity factors). This is evident by looking at hourly generation data, available from the EPA's Continuous Emissions Monitoring System, where one can observe considerable within-plant capacity factor variation over the course of a week or even a day.
} 
Results from five regressions based on the general form of equation (1) are given in Table 6. The structure of this table is the same as that for the heat rate and coal cost specifications - column 1 is the OLS results; column 2 is the GMM results instrumenting for $\log (\operatorname{cost}$ per KWh), share of NG generation, and share of oil generation; column 4 uses a balanced panel to check for the effect of plant exit on the results; column 5 uses a sample of IOs only. Again, all standard errors are clustered at the plant level.

The direct restructuring effect for IO plants (coefficient on Law Pass * IO) is negative, significant and quite similar across all specifications, while the restructuring effect for PO's is considerable smaller in magnitude and insignificant across all specifications. ${ }^{35}$ Since the dependent variable is $\log$ (capacity factor/(1-capacity factor)), the magnitude of this effect is not immediately apparent but the sign is consistent with capacity factors. ${ }^{36}$ The coefficient estimate on $\log (\operatorname{cost}$ per $\mathrm{kWh})$ is negative and statistically significant across specifications. These two effects display the countervailing impacts of restructuring on coal plants' capacity factors - the direct effect leads to a reduction of capacity factors, but restructuring also reduces the cost per KWh by reducing coal purchasing costs and heat rates and lower production costs is correlated with higher capacity factors. As discussed in more detail in the next section, the marginal effect of deregulation on capacity factors, inclusive of the impacts deregulation has on the cost per KWh and evaluated an 2005 mean values, is on a whole negative.

Because the common pre-treatment trend assumptions and general treatment dynamics appear more complicated for this specification, some additional discussion is warranted. The top panel in figure 3 shows the coefficient estimates on year fixed effects for the treatment group relative to the control group from 1992 to 2005 for all the observations. There is a continuing downward trend over time and the reduction in capacity factor is statistically significant from 1993, three years before the first restructuring law in 1996 (the first hearing occurred in 1993). This suggests that there might be pre-existing trend differences between the control and treatment groups, which would lead to over-estimation of the impact from restructuring. We explore this issue further and find, as mentioned above, that this is largely

\footnotetext{
${ }^{35}$ We have also re-run similar regressions by replacing the 'Law Pass' dummy with the 'RST' dummy used in the previous two regression settings, and the coefficient on Law Pass * IO is -0.26 for the baseline model (2) and it is statistically significant at 1 percent level.

${ }^{36}$ We can calculate the effect for a given heat rate. For example, for an average plant with a 60 percent capacity factor, the coefficient estimate of 0.29 implies a 12 percent reduction in capacity factor due to restructuring (approximately $0.29^{*}(1-0.6)$ ).
} 
driven by a few peak load plants. The bottom graph in 3 drops these peak load plants that have a capacity factor no larger than 0.2 (about the 5th percentile of the capacity factor distribution). Although the two graphs show similar pattern, there are two important differences. First, the coefficient estimates on interaction terms between year dummies and the treatment group dummy are smaller in magnitude in the bottom graph. Second, the coefficient estimates become statistically significant on a continuous basis only after 1997. It is important to note that the trend depicted by these coefficient estimates should not be viewed as the sole impact of restructuring on capacity factor. For example, figure 2 depicts a continuous reduction in the cost of coal from restructuring, which would counteract the downward trend in capacity factor. ${ }^{37}$

Finally, one may also be concerned that all of this estimated capacity factor reduction may be coming from plants with smaller capacities and thus no sizable generation reductions from coal plants in aggregate in deregulated compared to those in regulated regions actually occurs. To examine this further we augmented the base regression below by adding a variable that interacts $\mathrm{RST}^{*} \mathrm{IO}$ with a dummy variable equal to one if the plant's capacity is above the 75th percentile capacity level. The parameter on this interaction term was found to be small and insignificant, suggesting that there is no statistically different reaction to deregulation among smaller and larger plants. ${ }^{38}$

In the Appendix (Table A.1), we presented versions of column 2 in Table 6 where state level capacity factors (for gas and fuel oil) are replaced with NERC level ones as state level capacity factors may not predict very well the wholesale electricity prices when demand management is usually done at a larger geographical area. In one run the NERC level capacity factors are used, and in the other run both NERC level capacity factors and IVs are used. Results barely change for the first scenario; and when both controls and IVs are at the NERC level, the point estimate is slightly lower in magnitude: it drops from 0.29 to 0.175 , though it remains statistically significant.

\footnotetext{
${ }^{37}$ Figures 3 indicate that capacity factors for the treatment and the control groups depart before the start of the restructuring, suggesting that the control group may not be valid or it fails pre-treatment trend testings. Therefore, we use nearest neighbor matching techniques to match plants that never undergo restructuring to treated firms based on observables in one of the pre-treament years (from 1992 to 1995); the magnitude of Law Pass * IO ranges from 0.190 to 0.227 and they are all statistically significant at 5 percent level.

${ }^{38}$ One may still be concerned that if only the very large plants increased their capacity factors slightly that this would, in aggregate generation terms, negate capacity factor reductions from the other plants. Given the relatively few large plants this possibility seems unlikely.
} 


\section{Cost Savings and Environmental Impacts}

Given the parameters derived from the estimated equations above, we can derive back-ofthe-envelope calculations of cost savings and environmental benefits associated with restructuring. ${ }^{39}$ The calculations are summarized in Table 7 . Note that these values were based on average operation numbers from the last year of our data 2005 and using parameter estimates from column 2 of Table 3, column 2 of Table 4 , and column 2 of Table $6 .{ }^{40}$

We begin with the equations using $\log$ (heat rate) as the dependent variable. From this specification we find that restructuring leads to a 1.4 percent reduction in heat rates for IO plants. Using mean production values and pollution content of coal, as described in the Appendix, we calculate that the deregulation-induced efficiency improvements lead to per-plant annual emission reductions of 477 metric tons (mt) for $\mathrm{SO}_{2}, 220 \mathrm{mt}$ for $\mathrm{NO}_{X}$, and $82,511 \mathrm{mt}$ for $\mathrm{CO}_{2}$. The coal input savings brought about by the deregulation-induced heat rate improvement lead to an average annual per-plant cost savings of about $\$ 1.20$ million.

It should be noted that during part of the analysis period used in this study $\mathrm{SO}_{2}$ and $\mathrm{NO}_{X}$ were regulated under cap-and-trade systems. Thus, efficiency improvements, and the later-discussed capacity factor reductions, may not lead to an overall reduction in these pollutants if the caps are binding. However, there was considerable banking in both the $\mathrm{SO}_{2}$ and $\mathrm{NO}_{X}$ trading program, so the caps were not necessarily binding for either pollutant. The $\mathrm{NO}_{X}$ trading program had an explicit measure to limit the use of banked permits, called the progressive flow control, which made banked permit worth half of a contemporary permit, which was in force for a number of years. Additionally, even if the caps were annually binding, the implied emission reductions from efficiency improvements and capacity factor decreases, would lead to lower emission permit prices and thus still constitute some welfare gain due to lower compliance costs.

For the coal procurement results, the deregulation effect lowered per million Btu coal costs by 8.0 percent. The 2005 per-plant average annual savings from reduced coal-procurement costs brought about by restructuring were approximately $\$ 6.87$ million. The U.S. EPA's

\footnotetext{
${ }^{39}$ We consider these "back-of-the-envelope" calculations because we do not consider greater general equilibrium effects that would also be associated with restructuring. While not accounting for these general equilibrium effects obviously reduces the accuracy of the results presented below, we believe these cruder calculations are still useful in giving ballpark-estimates of the cost and environmental effects of restructuring for coal plants.

${ }^{40}$ We also made these calculations based on plant operation averages over the span 2001-2005. They were approximately the same as those presented below, so we exclude them for brevity's sake.
} 
Integrated Planning Model estimates that the average plant in our sample would pay $\$ 4$ per MWh for variable operating costs and $\$ 4000$ per MW in fixed operating cost. Using our sample average generation and capacity implies that the average plant has an annual operating expense of $\$ 55$ million in 2005 dollars. Combining the $\$ 1.20$ million in savings from fuel efficiency improvements and the $\$ 6.87$ million in savings from reduced cost of coal, IOs in restructured states have operating costs that is about 14 percent lower than similar plants under traditional regulation. ${ }^{41}$

As mentioned above, given the nature of the capacity factor equation (the form of the dependent variable and the fact that cost of generation is an explanatory variable), the effects of the change in capacity factors due to deregulation are slightly more complicated. Based on derived marginal effects described in the Appendix B and using the average 2005 values of relevant variables, we find that deregulation reduces capacity factors on average by 0.031 . That is, the direct deregulation effect outweighs the indirect effect of lower production costs brought about by deregulation.

With an average plant output of 5.77 million MWh's in 2005 for IOs in deregulated states, the calculated marginal effect on capacity factor implies deregulation reduced 2005 production from coal plants in deregulated states by an average of 303,349 MWh's per plant. Assuming constant total electricity production, the environmental benefits of a reduction in coal-plant generation will depend on what types of generators make up for this lost production. Given the generation profile of restructured states, it seems likely that the reduced coal-fired generation is substituted by generation from nuclear plants, natural gas plants, or some combination of these two. If we assume that effectively emissions-free nuclear plants supplant all the reduced coal-fired generation and using the same emission rates as given above, then the deregulation-induced change in capacity factors for coal plants reduced annual per-plant emissions by an average of $1789 \mathrm{mt}$ of $\mathrm{SO}_{2}, 825 \mathrm{mt}$ of $\mathrm{NO}_{X}$, and 309,542 $\mathrm{mt}$ of $\mathrm{CO}_{2}$. Note that these results imply that if reduced coal-fired generation is replaced with the nuclear generation, the emission savings from deregulation-induced reduction in capacity factors are greater than that from the deregulation-induced improved efficiency.

If instead we assume the reduced coal-fired production was replaced with natural gasfired generation, then the emissions savings are not as great. ${ }^{42}$ The effective average annual

\footnotetext{
${ }^{41}$ Whether these cost savings are rent transfers to power plants or welfare improvements is unknown here, but would be an interesting topic for future research.

${ }^{42}$ Note that if the restructuring-induced capacity factor reductions were caused by infra-marginal coal
} 
per-plant emissions reductions (i.e., reductions net of emissions from replacing natural gasfired generation) are $1775 \mathrm{mt}$ of $\mathrm{SO}_{2}, 591 \mathrm{mt}$ of $\mathrm{NO}_{X}$, and 153,326 mt of $\mathrm{CO}_{2}$. While the emission reductions under the natural gas-replacement assumption are not as large as those from the improved efficiency, they still represent sizable emission reductions. Determining the cost of such reductions, as well as the validity of the replacement assumption, would require a more in-depth market study that is beyond the scope of the current work.

\section{Conclusion}

Starting from mid 1990's, about half of the U.S. states passed legislation to restructure their electricity industry with the goal of reducing electricity costs to ratepayers by increasing competition. In this paper, we provide a further investigation on the impacts of this restructuring. Our study differs from previous literature in the following four aspects: (1) a longer data period than what has been previously used allows us to examine the effects in both the short and medium run; (2) focusing on coal-fired power plants avoids confounding factors from different generation technologies; (3) we examine the impacts on three aspects of plant operation: plant efficiency, coal price, and utilization; and (4) based on estimation results, we quantify the environmental impacts of restructuring.

Our analysis suggests a 1.4 percent improvement in the heat rate after restructuring among IOs in states that carried out restructuring relative to IOs in states without restructuring. These figures are consistent with other studies of heat rate such as Bushnell and Wolfram (2005). We find that the cost of coal purchased on per unit heat basis has decreased among IOs in states with restructured markets by 8 percent relative to coal with similar characteristics purchased by plants in cost of service regions. Additionally, states which started but stopped restructuring show little, if any, change in plant performance relative to those which implemented restructuring. Finally, our estimates show that the net marginal effect of restructuring has led to a reduction of capacity factor for IOs in deregulated regions relative to their cost of service counterparts.

To put our parameter estimates into context, we also calculated per-plant annual savings and emission reductions associated with restructuring. We found, due to deregulation

plants trying to put even higher cost generators on the margin, then it would seem that natural gas, and not low-marginal cost nuclear, generation would supplant the coal generation. Also, for these calculations we assume average emission rates for natural gas plants of $0.1 \mathrm{lbs}$ of $\mathrm{SO}_{2} / \mathrm{MWh}, 1.7 \mathrm{lbs}$ ofNO $\mathrm{X} / \mathrm{MWh}$, and 1,135 lbs of $\mathrm{CO}_{2} / \mathrm{MWh}$. 
induced efficiency improvements and reductions in cost of coal, IO plants in restructured region had an average annual cost savings of $\$ 1.20$ million and $\$ 6.87$ million, respectively. The combined savings are nearly $15 \%$ of an average plants operating expenses. Both efficiency improvement and reduction in capacity factor in coal-fired power plants lead to emissions reductions. Depending on how much the generation from coal-fired plants are replace by natural gas or nuclear plants, the emissions reduction are likely to be around 2,266 mt for $\mathrm{SO}_{2}$ (7.55 percent), between 811 and $1045 \mathrm{mt}$ for $\mathrm{NO}_{X}$ (5.89-7.55 percent), and between 235,837-392,053 mt for $\mathrm{CO}_{2}$ (4.6-7.55 percent).

While our study contributes to the literature by bringing new evidence to bear, it also points to several directions for future research. First, it would be interesting to further investigate the importance of market power in the change of capacity factors after restructuring. Second, whether these results can be generalized to other power plants such as natural gas power plants should be addressed in the future. Third, what has been the impact of increased bargaining power by plants for coal on coal mines, if indeed this is the cause of the lower coal purchasing costs we find? Fourth, has electricity restructuring reduced the environmental impact of coal plants? Improved efficiency would suggest that it has, but the reduction in costs may more than offset the efficiency gain. A more complete general equilibrium analysis is required to fully understand these trade-offs. Finally, the empirical literature including this analysis, do not analyze the effect of restructuring on investment, adoption of new technologies or entry and exit. The impact of restructuring on these important factors remains to be examined. 


\section{References}

Bellas, Allen and Ian Lange, "The 1990 Clean Air Act and the Implicit Price of Sulfur in Coal," The B.E. Journal of Economic Analysis and Policy, 2007, 7 (1).

Bonskowski, Richard, "The U.S. Coal Industry in the 1990's: Low Prices and Record Production," 1999. Energy Information Administration.

Borenstein, S., M. Busse, and R. Kellogg, "Career Concerns, Inaction, and Market Inefficiency: Evidence from Utility Regulation," Journal of Industrial Economics, 2012, 60 (2), 220-248.

Borenstein, Severin, James Bushnell, and Frank Wolak, "Measuring Market Inefficiencies in Californias Restructured Wholesale Electricity Market," American Economic Review, 2002, 92, 1376-1405.

Bushnell, James and Catherine D. Wolfram, "Ownership Change, Incentives and Plant Efficiency: The Divestiture of U.S. Electric Generation Plants," 2005. Center for the Study of Energy Markets WP 140.

Cicala, Steve, "When Does Regulation Distort Costs? Lessons from Fuel Procurement in U.S. Electricity Generation," American Economic Review, 2015, 105 (1), 411-444.

Cropper, Maureen L., Alexander Limonov, Kabir Malik, and Anoop Singh, "Estimating the Impact of Restructuring on Electricity Generation Efficiency: The Case of the Indian Thermal Power Sector," 2011. NBER Working Paper, \#17383.

Davis, Lucas W. and Catherine D. Wolfram, "Deregulation, Consolidation, and Efficiency: Evidence from U.S. Nuclear Power," American Economic Journal: Applied Economics, 2012, 4 (4), 194-225.

_ and Lutz Kilian, "The Allocative Cost of Price Ceilings in the U.S. Residential Market for Natural Gas," Journal of Political Economy, 2011, 119 (2), 212-241.

Douglas, Stratford, "Measuring Gains from Regional Dispatch: Coal-Fired Power Plant Utilization and Market Reforms," The Energy Journal, 2006, 27 (1), 119-138.

Fabrizio, Kira, Nancy Rose, and Catherine D. Wolfram, "Do Markets Reduce Costs? Assessing the Impact of Regulatory Restructuring on US Electric Generation Efficiency," American Economic Review, 2007, 97 (4), 1250-1277. 
Fowlie, Meredith, "Emissions Trading, Electricity Restructuring, and Investment in Pollution Abatement," American Economic Review, 2010, 100 (3), 837-869.

Hortaçsu, Ali and Steven L. Puller, "Understanding strategic bidding in multi-unit auctions: a case study of the Texas electricity spot market," RAND Journal of Economics, 2008, 39 (1), 86-114.

Knittel, Christopher, "Alternative Regulatory Methods and Firm Efficiency: Stochastic Frontier Evidence the US Electricity Industry," The Review of Economics and Statistics, $2002,84(3), 530-540$.

Laffont, Jean-Jacques and Jean Tirole, A Theory of Incentives in Procurement and Regulation, MIT Press, 1993.

Linn, Joshua, Erin Mastrangelo, and Dallas Burtraw, "Regulating Greenhouse Gases from Coal Power Plants under the Clean Air Act," Journal of the Association of Environmental and Resource Economists, 2014.

Mansur, Erin, "Upstream Competition and Vertical Integration in Electricity Markets," Journal of Law and Economics, 2007, 50 (1), 125-156.

_, "Measuring Welfare in Restructured Electricity Markets," Review of Economics and Statistics, 2008, 90 (2), 369-386.

Muller, Nicholas Z., Robert Mendelsohn, and William Nordhaus, "Environmental Accounting for Pollution in the United States Economy," American Economic Review, 2011, 101 (5), 1649-1675.

Newbery, David M. and Michael G. Pollitt, "The Restructuring and Privatisation of Britain's CEGB - Was It Worth It?," Journal of Industrial Economics, 1997, 45 (3), 269-303.

Olley, Steven and Ariel Pakes, "The Dynamics of Productivity in the Telecommunications Equipment Industry," Econometrica, 1996, 64, 1263-1297.

Syverson, Chad, "Market Structure and Productivity: A Concrete Example," Journal of Political Economy, 2004, 112 (6), 1181-1222.

White, Matthew, "Power Struggles: Explaining Deregulatory Reforms in Electricity Markets," Brookings Papers on Economic Activity. Microeconomics, 1996, pp. 201-250. 
Wolfram, Catherine D., "Measuring Duopoly Power in the British Electricity Spot Market," American Economic Review, 1999, 89 (4), 805-826.

Zhang, Fan, "Does Electricity Restructuring Work? Evidence From the U.S. Nuclear Energy Industry," Journal of Industrial Economics, 2007, 55 (3), 397-418. 
Figure 1: Time Effect of Heat Rate in Treatment Group

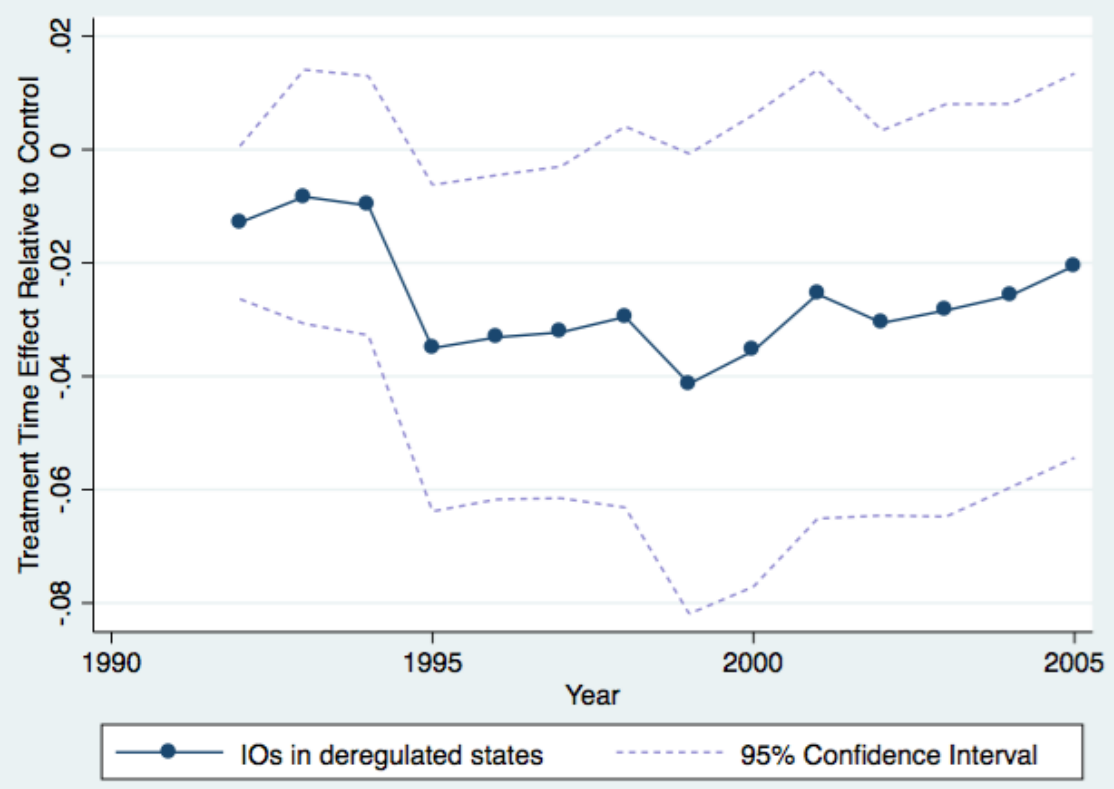

Note: The figure plots the time effect of the heat rate for the treatment group relative to the control group conditional on plants fixed effects and observables.

Figure 2: Time Effect of Unit Heat Cost in Treatment Group

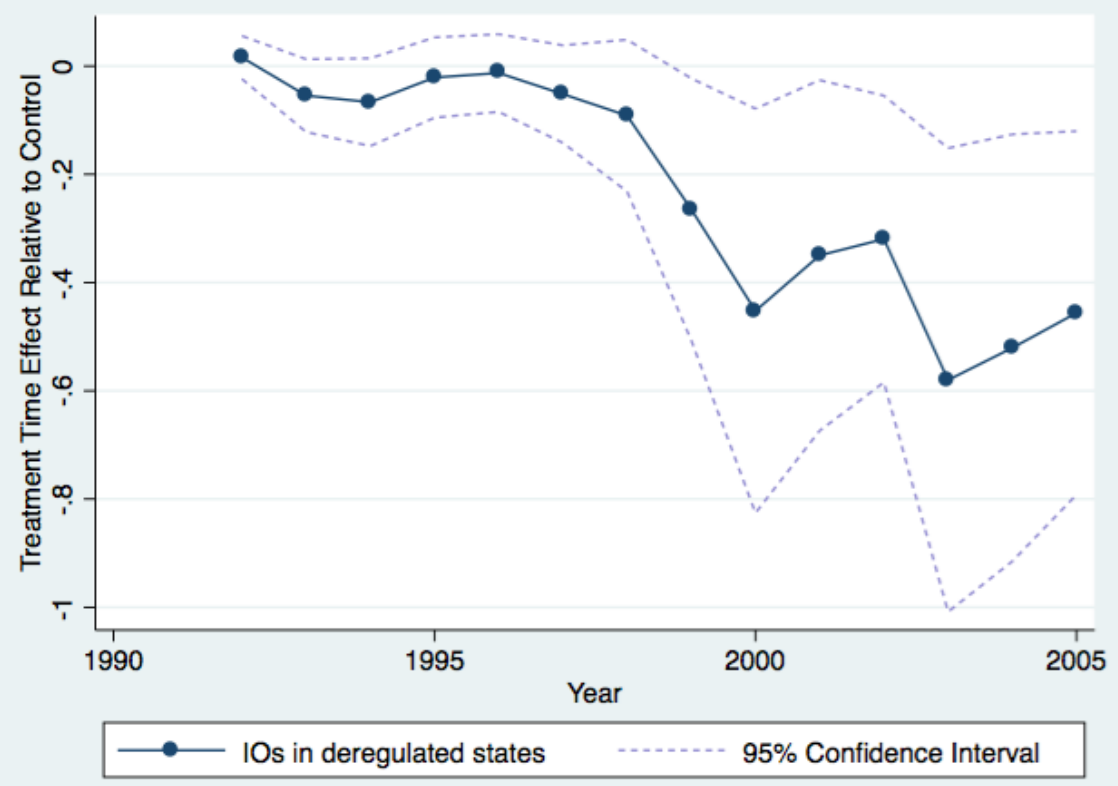

Note: The figure plots the time effect of the unit heat cost for the treatment group relative to the control group conditional on plants fixed effects and observables. 
Figure 3: Time Effect of Capacity Factor in Treatment Group
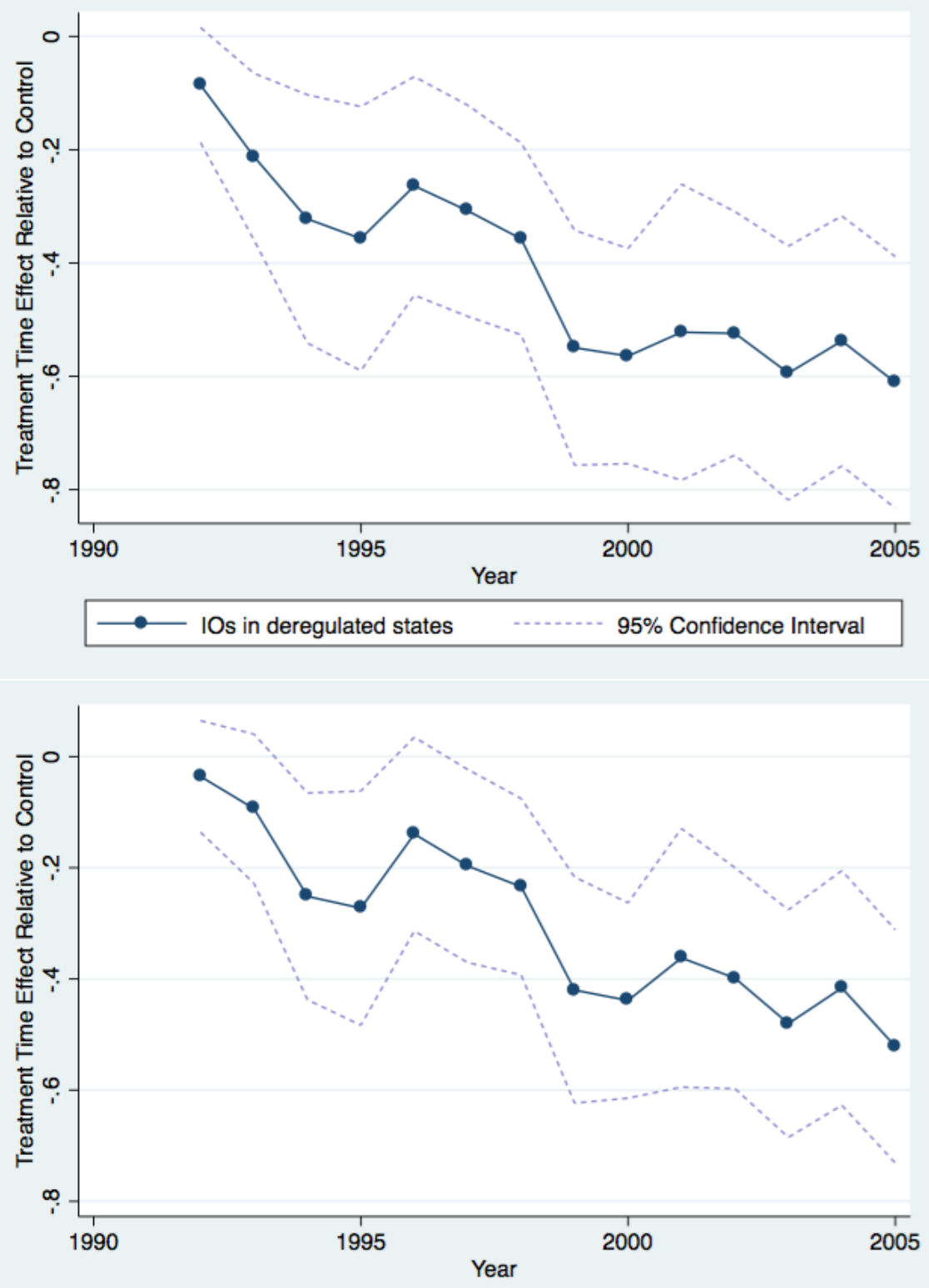

IOs in deregulated states

95\% Confidence Interval

Note: The figures plot the time effect of capacity factor/(1-capacity factor) for the treatment group relative to the control group conditional on plants fixed effects and observables. The top figure is base on the full sample while the bottom one is based on a restricted sample constructed by dropping marginal plants (e.g., capacity factor no larger than 0.2 , the 5 th percentile of the distribution). 
Table 1: Restructured States

\begin{tabular}{ccccc}
\hline State & Hearing & Passed & Suspended & Avg. Plants \\
\hline CA & 1994 & 1996 & - & 0 \\
CT & 1994 & 1998 & - & 1 \\
DC & 1996 & 2000 & - & 0 \\
DE & 1995 & 1999 & - & 2 \\
IL & 1995 & 1997 & - & 24 \\
MA & 1994 & 1997 & - & 4 \\
MD & 1995 & 1999 & - & 7 \\
ME & 1995 & 1997 & - & 0 \\
MI & 1994 & 2000 & - & 21 \\
MT & 1996 & 1997 & - & 3 \\
NH & 1994 & 1996 & - & 2 \\
NJ & 1996 & 1999 & - & 5 \\
NY & 1993 & 1996 & - & 11 \\
OH & 1996 & 1999 & - & 26 \\
OR & 1995 & 1999 & - & 1 \\
PA & 1994 & 1996 & - & 21 \\
RI & 1994 & 1996 & - & 0 \\
TX & 1997 & 1999 & - & 18 \\
AR & 1997 & 1999 & 2003 & 3 \\
AZ & 1995 & 1998 & 2004 & 6 \\
IN & 1995 & - & - & 24 \\
KY & 1996 & 1999 & 2000 & 20 \\
NM & 1995 & 1999 & 2003 & 3 \\
NV & 1994 & 1996 & 2001 & 3 \\
OK & 1995 & 1997 & 2001 & 5 \\
VA & 1995 & 1999 & 2002 & 9 \\
WV & 1995 & 1999 & 2000 & 13 \\
\hline & & 3 \\
\hline
\end{tabular}

Note: "Avg. Plant" refers to the yearly average number plants based on all the observations used in the baseline analyses. The list of states and year of the hearings is based on the treatment group and timing given in Fabrizio et al. (2007). The year of legislation passage and repeal or suspension of restructuring is based on data provided by the Energy Information Administration's (EIA) Status of Electricity Restructuring (http://www.eia.gov/cneaf/electricity/page/restructuring/restructure_elect.html). Note that the EIA list California and Montana as having suspended restructuring. Both states forced integrated-utilities to divest some generation capacity and have some form of competitive wholesale markets. We thus treat CA and MT as restructured states for our analysis. The robustness of this configuration is tested in our analysis. 
Table 2: Summary Statistics

\begin{tabular}{lcccc}
\hline & \multicolumn{2}{c}{ Deregulated IOs } & \multicolumn{2}{c}{ Rest of Plants } \\
& Before & After & Before & After \\
\hline Heat Rate & 10654.59 & 10638.17 & 11129.56 & 11183.86 \\
& $(1232.89)$ & $(1303.81)$ & $(1754.72)$ & $(1760.03)$ \\
Unit Heat Cost & 153.11 & 141.49 & 133.12 & 129.09 \\
& $(41.45)$ & $(32.92)$ & $(37.82)$ & $(41.38)$ \\
Capacity Factor & 0.55 & 0.59 & 0.52 & 0.62 \\
Output (in GWh) & $(0.18)$ & $(0.17)$ & $(0.20)$ & $(0.17)$ \\
& 4668.85 & 4669.35 & 3909.35 & 4501.95 \\
Scrubber & $4329.89)$ & $(4422.14)$ & $(4142.48)$ & $(4525.99)$ \\
Sulfur Content & 0.19 & 0.18 & 0.26 & 0.31 \\
Spot Share & $(0.39)$ & $(0.39)$ & $(0.44)$ & $(0.46)$ \\
& 1.77 & 1.50 & 1.60 & 1.37 \\
Phase I ARP & $(1.27)$ & $(1.13)$ & $(1.28)$ & $(1.21)$ \\
& 0.25 & 0.30 & 0.26 & 0.22 \\
NOx NBP & $(0.30)$ & $(0.32)$ & $(0.32)$ & $(0.31)$ \\
& 0.04 & 0.19 & 0.12 & 0.07 \\
& $(0.19)$ & $(0.39)$ & $(0.33)$ & $(0.25)$ \\
& 0.00 & 0.33 & 0.00 & 0.11 \\
& $(0.00)$ & $(0.47)$ & 0.00 & $(0.31)$ \\
\hline
\end{tabular}

Note: The summary statistics are computed based on all the observations used in the baseline analyses. Standard deviations are shown in the parentheses underneath. The estimation sample contains 418 plants, 310 of which are IOs and 108 that are POs. 122 of the 310 IO plants and 23 of the 103 PO plants are part of the treatment. Respective data sources are described in Section 3. For the treatment group (IOs in deregulated states), 'before' are all the observations before restructuring took place. For the control group (regulated and POs in deregulated states, 'before' is arbitrarily set to represent observations before 1998, the weighted average of the year for restructuring. Heat rate is in MMBtu per $\mathrm{kWh}$ and Unit heat cost is in cents per MMBtu. 
Table 3: Heat Rate Regression

\begin{tabular}{lcccc}
\hline & $(1)$ & $(2)$ & $(3)$ & $(4)$ \\
& OLS & GMM IV & GMM IV & GMM IV-IOs Only \\
\hline RST*IO & $-0.014^{* * *}$ & $-0.014^{* *}$ & $-0.014^{* *}$ & $-0.017^{* *}$ \\
& $(0.005)$ & $(0.007)$ & $(0.006)$ & $(0.007)$ \\
RST*PO & -0.013 & -0.011 & -0.009 & \\
Log(Output) & $(0.012)$ & $(0.013)$ & $(0.013)$ & \\
& $-0.073^{* * *}$ & -0.083 & -0.089 & $-0.103^{*}$ \\
Divestiture in regulated state & $(0.00)$ & $(0.053)$ & $(0.058)$ & $(0.056)$ \\
& 0.003 & 0.008 & $0.027^{* *}$ & $0.025^{*}$ \\
Incentive regulation & $(0.011)$ & $(0.011)$ & $(0.012)$ & $(0.014)$ \\
& 0.009 & -0.004 & -0.003 & -0.000 \\
Phase I ARP & $(0.007)$ & $(0.004)$ & $(0.005)$ & $(0.006)$ \\
& 0.006 & 0.007 & 0.006 & 0.008 \\
Scrubber & $(0.004)$ & $(0.005)$ & $(0.005)$ & $(0.006)$ \\
& -0.008 & -0.009 & -0.008 & -0.014 \\
NO $X$ programs & $(0.008)$ & $(0.008)$ & $(0.008)$ & $(0.010)$ \\
Log(capacity) & $0.007^{*}$ & 0.008 & 0.008 & 0.007 \\
Log(capacity) Sq & $(0.004)$ & $(0.006)$ & $(0.006)$ & $(0.007)$ \\
& $-0.424^{* * *}$ & -0.035 & -0.087 & 0.271 \\
Number of IVs & $(0.077)$ & $(0.191)$ & $(0.217)$ & $(0.545)$ \\
Underid. P-value & $0.018^{* * *}$ & 0.004 & 0.007 & -0.008 \\
Overid. P-value & $(0.003)$ & $(0.007)$ & $(0.009)$ & $(0.022)$ \\
\hline Observations & No & 6 & 6 & 6 \\
\hline Not The & & 0.028 & 0.047 & 0.024 \\
& & 0.361 & 0.372 & 0.689 \\
\hline
\end{tabular}

Note: The dependent variable is $\log ($ Unit Heat Rate).All regressions include plant fixed effects and year fixed effects in addition to variables shown. Columns 2-4 use 6 IVs: $\log$ (state electricity sales), $\log$ (state gross product), $\log$ (housing starts), and their interaction terms with the share of state electricity generation capacity from coal. Columns 1 through 3 also include PO-specific year fixed effects. Standard errors are clustered at the plant level. Results for other specifications are available in Table 5. *, **, and *** indicate significance at the 10,5 , and 1 percent levels. We report p-values for the underidentification test based on Kleibergen-Paap rk LM statistic and the overidentificiation test based on Hansen J-Statistic. Column 2 is the benchmark specification. Column 3 focus on plants that stayed in the data throughout. Column 4 uses only IOs. Phase II of the acid rain program (ARP) applies to all coal-fired power plants so its effect is captured by year fixed effects. 
Table 4: Effect on Unit Heat Cost

\begin{tabular}{|c|c|c|c|c|}
\hline & $\begin{array}{l}(1) \\
\text { OLS }\end{array}$ & $\begin{array}{c}(2) \\
\text { GMM IV }\end{array}$ & $\begin{array}{c}(3) \\
\text { GMM IV }\end{array}$ & $\begin{array}{c}(4) \\
\text { GMM IV-IOs Only }\end{array}$ \\
\hline $\mathrm{RST}^{*} \mathrm{IO}$ & $\begin{array}{c}0.004 \\
(0.013)\end{array}$ & $\begin{array}{c}-0.080^{* * *} \\
(0.030)\end{array}$ & $\begin{array}{c}-0.084^{* *} \\
(0.035)\end{array}$ & $\begin{array}{c}-0.053^{* *} \\
(0.025)\end{array}$ \\
\hline $\mathrm{RST}^{*} \mathrm{PO}$ & $\begin{array}{c}0.020 \\
(0.036)\end{array}$ & $\begin{array}{c}0.036 \\
(0.055)\end{array}$ & $\begin{array}{c}0.040 \\
(0.058)\end{array}$ & \\
\hline Log(BTUs purchased) & $\begin{array}{c}-0.026^{* * *} \\
(0.010)\end{array}$ & $\begin{array}{c}-0.344^{* * *} \\
(0.118)\end{array}$ & $\begin{array}{c}-0.399^{* * *} \\
(0.153)\end{array}$ & $\begin{array}{c}-0.246^{* *} \\
(0.103)\end{array}$ \\
\hline Share from spot market & $\begin{array}{c}-0.063^{* * *} \\
(0.014)\end{array}$ & $\begin{array}{c}0.403^{* * *} \\
(0.155)\end{array}$ & $\begin{array}{c}0.443^{* * *} \\
(0.169)\end{array}$ & $\begin{array}{c}0.341^{* *} \\
(0.149)\end{array}$ \\
\hline Divestiture in regulated state & $\begin{array}{c}-0.226^{* *} \\
(0.104)\end{array}$ & $\begin{array}{c}-0.357^{* * *} \\
(0.129)\end{array}$ & $\begin{array}{c}-0.425^{* *} \\
(0.178)\end{array}$ & $\begin{array}{c}-0.279^{* *} \\
(0.109)\end{array}$ \\
\hline Incentive regulation & $\begin{array}{c}0.069^{* * *} \\
(0.024)\end{array}$ & $\begin{array}{c}0.008 \\
(0.018)\end{array}$ & $\begin{array}{c}0.017 \\
(0.019)\end{array}$ & $\begin{array}{c}0.021 \\
(0.020)\end{array}$ \\
\hline Sulfur content & $\begin{array}{c}-0.026^{* *} \\
(0.010)\end{array}$ & $\begin{array}{l}0.008 \\
(0.015)\end{array}$ & $\begin{array}{c}0.010 \\
(0.016)\end{array}$ & $\begin{array}{c}0.011 \\
(0.015)\end{array}$ \\
\hline Ash content & $\begin{array}{c}0.016^{* * *} \\
(0.004)\end{array}$ & $\begin{array}{l}0.011^{* *} \\
(0.004)\end{array}$ & $\begin{array}{c}0.013^{* * *} \\
(0.005)\end{array}$ & $\begin{array}{c}0.015^{* * *} \\
(0.005)\end{array}$ \\
\hline Phase I ARP & $\begin{array}{c}0.002 \\
(0.011)\end{array}$ & $\begin{array}{c}0.021 \\
(0.023)\end{array}$ & $\begin{array}{c}0.019 \\
(0.013)\end{array}$ & $\begin{array}{c}0.013 \\
(0.019)\end{array}$ \\
\hline Scrubber & $\begin{array}{l}-0.008 \\
(0.033)\end{array}$ & $\begin{array}{l}-0.041 \\
(0.047)\end{array}$ & $\begin{array}{l}-0.043 \\
(0.034)\end{array}$ & $\begin{array}{l}-0.025 \\
(0.044)\end{array}$ \\
\hline $\mathrm{SO}_{2}$ trade* sulfur content & $\begin{array}{c}0.000 \\
(0.008)\end{array}$ & $\begin{array}{c}-0.022^{* *} \\
(0.011)\end{array}$ & $\begin{array}{l}-0.021^{*} \\
(0.012)\end{array}$ & $\begin{array}{l}-0.021 \\
(0.014)\end{array}$ \\
\hline Scrubber*sulfur content & $\begin{array}{c}0.011 \\
(0.019)\end{array}$ & $\begin{array}{c}0.039^{* *} \\
(0.017)\end{array}$ & $\begin{array}{c}0.037^{* *} \\
(0.019)\end{array}$ & $\begin{array}{c}0.029 \\
(0.019)\end{array}$ \\
\hline Log(capacity) & $\begin{array}{l}-0.417 \\
(0.263)\end{array}$ & $\begin{array}{c}-2.138^{* * *} \\
(0.673)\end{array}$ & $\begin{array}{c}-2.352^{* * *} \\
(0.769)\end{array}$ & $\begin{array}{c}-2.601^{* *} \\
(1.112)\end{array}$ \\
\hline Log(capacity) Sq & $\begin{array}{c}0.020^{* *} \\
(0.010)\end{array}$ & $\begin{array}{c}0.084^{* * *} \\
(0.028)\end{array}$ & $\begin{array}{c}0.093^{* * *} \\
(0.032)\end{array}$ & $\begin{array}{c}0.101^{* *} \\
(0.044)\end{array}$ \\
\hline No. of IVs & No & 6 & 6 & 6 \\
\hline Underid. P-value & & 0.043 & 0.145 & 0.087 \\
\hline Overid. P-value & & 0.322 & 0.426 & 0.038 \\
\hline Observations & 5334 & 5334 & 5239 & 3972 \\
\hline
\end{tabular}

Note: The dependent variable is $\log ($ Unit Heat Cost). All regressions include plant fixed effects and year fixed effects in addition to variables shown. Columns 2-4 use 6 IVs: $\log$ (state electricity sales), $\log$ (state gross product), $\log$ (housing starts), and their interaction terms with the share of state electricity generation capacity from coal. Columns 1 through 3 also include PO-specific year fixed effects. Standard errors are clustered at the plant level. Results for other specifications are available in Table 5. *, **, and *** indicate significance at the 10,5 , and 1 percent levels. We report p-values for the underidentification test based on Kleibergen-Paap rk LM statistic and the overidentificiation test based on Hansen J-Statistic. Column 2 is the benchmark specification. Column 3 focus on plants that stayed in the data throughout. Column 4 uses only IOs. Phase II of the acid rain program (ARP) applies to all coal-fired power plants so its effect is captured by year fixed effects. 
Table 5: Robustness Checks for Heat Rate and Unit Cost

\begin{tabular}{|c|c|c|c|c|c|}
\hline Specification & State Cluster & Hearing & Hearing & Law Pass & East Only \\
\hline \multicolumn{6}{|c|}{ Heat Rate Equation } \\
\hline $\mathrm{RST} * \mathrm{IO}$ & $\begin{array}{c}-0.018^{* * *} \\
(0.004)\end{array}$ & $\begin{array}{c}-0.016^{* *} \\
(0.007)\end{array}$ & $\begin{array}{c}-0.016^{* *} \\
(0.007)\end{array}$ & $\begin{array}{l}-0.013 \\
(0.008)\end{array}$ & $\begin{array}{c}-0.013^{* *} \\
(0.006)\end{array}$ \\
\hline $\mathrm{RST}_{1} * \mathrm{IO}$ & & $\begin{array}{l}-0.006 \\
(0.006)\end{array}$ & & & \\
\hline $\mathrm{RST}_{2} * \mathrm{IO}$ & & & $\begin{array}{c}-0.009^{*} \\
(0.005)\end{array}$ & & \\
\hline Observations & 5936 & 5936 & 5936 & 5936 & 3804 \\
\hline \multicolumn{6}{|c|}{ Unit Heat Cost Equation } \\
\hline $\mathrm{RST} * \mathrm{IO}$ & $\begin{array}{c}-0.082^{*} \\
(0.043)\end{array}$ & $\begin{array}{c}-0.091^{* * *} \\
(0.033)\end{array}$ & $\begin{array}{c}-0.092^{* * *} \\
(0.034)\end{array}$ & $\begin{array}{c}-0.127^{* *} \\
(0.060)\end{array}$ & $\begin{array}{c}-0.054^{*} \\
(0.032)\end{array}$ \\
\hline $\mathrm{RST}_{1} * \mathrm{IO}$ & & $\begin{array}{l}-0.014 \\
(0.028)\end{array}$ & & & \\
\hline $\mathrm{RST}_{2} * \mathrm{IO}$ & & & $\begin{array}{l}-0.032 \\
(0.023)\end{array}$ & & \\
\hline Observations & 5334 & 5334 & 5334 & 5334 & 3386 \\
\hline
\end{tabular}

Note: All columns are GMM IV regressions and include plant fixed effects and year fixed effects in addition to variables shown in Tables 3 and 4. All columns use 6 IVs: $\log$ (state electricity sales), $\log$ (state gross product), $\log$ (housing starts), and their interaction terms with the share of state electricity generation capacity from coal. The first column clusters the standard errors by state. "RST $1 * \mathrm{IO}$ " is equal to one for IO plants after a hearing in states that FRW list as restructured but did not in fact implement restructuring. " $\mathrm{RST}_{2} * \mathrm{IO}$ " is the same "RST ${ }_{1} * \mathrm{IO}$ " but it becomes a zero when restructuring legislation is repealed. Column 4 uses a "LawPassit" for the restructuring dummy, turning to one when the state passes restructuring legisation instead of holds hearings to rule out anticipatory effects from restructuring. "East Only" considers plants in the Census Regions of East North Central, East South Central, Middle Atlantic, New England, and South Atlantic. 
Table 6: Effect on Capacity Utilization

\begin{tabular}{|c|c|c|c|c|c|}
\hline & $\begin{array}{l}(1) \\
\text { OLS }\end{array}$ & $\begin{array}{c}(2) \\
\text { GMM IV }\end{array}$ & $\begin{array}{c}(3) \\
\text { GMM IV }\end{array}$ & $\begin{array}{c}(4) \\
\text { GMM IV }\end{array}$ & $\begin{array}{c}(5) \\
\text { GMM IV }\end{array}$ \\
\hline Law Pass $*$ IO & $\begin{array}{c}-0.280^{* * *} \\
(0.057)\end{array}$ & $\begin{array}{c}-0.290^{* * *} \\
(0.065)\end{array}$ & $\begin{array}{c}-0.290^{* * *} \\
(0.074)\end{array}$ & $\begin{array}{c}-0.271^{* * *} \\
(0.065)\end{array}$ & $\begin{array}{c}-0.232^{* * *} \\
(0.065)\end{array}$ \\
\hline Law Pass $*$ PO & $\begin{array}{c}-0.168 \\
(0.103)\end{array}$ & $\begin{array}{c}-0.177 \\
(0.115)\end{array}$ & $\begin{array}{c}-0.177 \\
(0.135)\end{array}$ & $\begin{array}{c}-0.170 \\
(0.116)\end{array}$ & \\
\hline $\log ($ cost per KWh $)$ & $\begin{array}{c}-0.761^{* * *} \\
(0.095)\end{array}$ & $\begin{array}{l}-1.469^{*} \\
(0.778)\end{array}$ & $\begin{array}{l}-1.469 \\
(0.913)\end{array}$ & $\begin{array}{l}-1.514^{*} \\
(0.797)\end{array}$ & $\begin{array}{l}-0.926 \\
(0.657)\end{array}$ \\
\hline State capacity factor for $\mathrm{NG}$ & $\begin{array}{c}0.026^{* *} \\
(0.012)\end{array}$ & $\begin{array}{l}0.084 \\
(0.115)\end{array}$ & $\begin{array}{c}0.084 \\
(0.127)\end{array}$ & $\begin{array}{c}0.090 \\
(0.115)\end{array}$ & $\begin{array}{c}0.107 \\
(0.111)\end{array}$ \\
\hline State capacity factor for oil & $\begin{array}{c}0.007 \\
(0.008)\end{array}$ & $\begin{array}{c}0.013 \\
(0.048)\end{array}$ & $\begin{array}{c}0.013 \\
(0.059)\end{array}$ & $\begin{array}{c}0.008 \\
(0.049)\end{array}$ & $\begin{array}{c}0.028 \\
(0.054)\end{array}$ \\
\hline Divestiture in regulated state & $\begin{array}{c}0.138 \\
(0.097)\end{array}$ & $\begin{array}{c}0.135 \\
(0.113)\end{array}$ & $\begin{array}{c}0.135 \\
(0.109)\end{array}$ & $\begin{array}{c}0.118 \\
(0.128)\end{array}$ & $\begin{array}{c}0.030 \\
(0.155)\end{array}$ \\
\hline Incentive regulation & $\begin{array}{l}-0.072 \\
(0.055)\end{array}$ & $\begin{array}{l}-0.057 \\
(0.068)\end{array}$ & $\begin{array}{l}-0.057 \\
(0.081)\end{array}$ & $\begin{array}{l}-0.045 \\
(0.070)\end{array}$ & $\begin{array}{c}0.005 \\
(0.072)\end{array}$ \\
\hline Log(NG price) & $\begin{array}{c}0.041 \\
(0.062)\end{array}$ & $\begin{array}{c}0.065 \\
(0.092)\end{array}$ & $\begin{array}{c}0.065 \\
(0.109)\end{array}$ & $\begin{array}{c}0.069 \\
(0.093)\end{array}$ & $\begin{array}{c}0.041 \\
(0.105)\end{array}$ \\
\hline Log(NG price)* \% state NG capacity & $\begin{array}{c}0.068 \\
(0.043)\end{array}$ & $\begin{array}{l}0.083^{*} \\
(0.046)\end{array}$ & $\begin{array}{c}0.083 \\
(0.070)\end{array}$ & $\begin{array}{l}0.077^{*} \\
(0.045)\end{array}$ & $\begin{array}{c}0.156^{* * *} \\
(0.053)\end{array}$ \\
\hline Phase I ARP & $\begin{array}{l}-0.021 \\
(0.033)\end{array}$ & $\begin{array}{l}-0.025 \\
(0.054)\end{array}$ & $\begin{array}{l}-0.025 \\
(0.057)\end{array}$ & $\begin{array}{l}-0.035 \\
(0.055)\end{array}$ & $\begin{array}{l}-0.071 \\
(0.053)\end{array}$ \\
\hline Scrubber & $\begin{array}{c}0.050 \\
(0.077)\end{array}$ & $\begin{array}{c}0.066 \\
(0.080)\end{array}$ & $\begin{array}{c}0.066 \\
(0.080)\end{array}$ & $\begin{array}{c}0.066 \\
(0.080)\end{array}$ & $\begin{array}{c}0.007 \\
(0.091)\end{array}$ \\
\hline NOx programs & $\begin{array}{l}-0.058 \\
(0.041)\end{array}$ & $\begin{array}{c}0.035 \\
(0.082)\end{array}$ & $\begin{array}{c}0.035 \\
(0.109)\end{array}$ & $\begin{array}{c}0.043 \\
(0.085)\end{array}$ & $\begin{array}{c}0.027 \\
(0.069)\end{array}$ \\
\hline Log(capacity) & $\begin{array}{l}-1.519 \\
(2.274)\end{array}$ & $\begin{array}{l}-2.127 \\
(2.231)\end{array}$ & $\begin{array}{l}-2.127 \\
(2.686)\end{array}$ & $\begin{array}{l}-2.314 \\
(2.272)\end{array}$ & $\begin{array}{l}-5.285 \\
(5.360)\end{array}$ \\
\hline $\log$ (capacity) Sq & $\begin{array}{c}0.008 \\
(0.090)\end{array}$ & $\begin{array}{c}0.032 \\
(0.088)\end{array}$ & $\begin{array}{c}0.032 \\
(0.106)\end{array}$ & $\begin{array}{c}0.038 \\
(0.089)\end{array}$ & $\begin{array}{c}0.151 \\
(0.206)\end{array}$ \\
\hline $\begin{array}{l}\text { Underid. P-value } \\
\text { Overid. P-value }\end{array}$ & & $\begin{array}{l}0.00 \\
0.94\end{array}$ & $\begin{array}{l}0.46 \\
0.97\end{array}$ & $\begin{array}{l}0.01 \\
0.92\end{array}$ & $\begin{array}{l}0.00 \\
0.75\end{array}$ \\
\hline Observations & 5055 & 5054 & 5054 & 4949 & 3725 \\
\hline
\end{tabular}

Note: The dependent variable is $\log [$ Capacity Factor/(1-Capacity Factor)]. All regressions include and include plant fixed effects and year fixed effects in addition to variables shown. Columns 1 through 4 also include PO-specific year fixed effects. Standard errors are clustered at the plant level except Column 3 which clusters at the state level. Columns 2-5 use 6 IVs: $\log$ (state electricity sales), $\log$ (state gross product), $\log$ (housing starts), and their interaction terms with the share of state electricity generation capacity from coal. Column 2 is the benchmark specification. Column 3 clusters the standard errors at the state level. Column 4 focus on plants that stayed in the data throughout. Column 5 uses only IOs. Phase II of the acid rain program (ARP) applies to all coal-fired power plants so its effect is captured by year fixed effects. 
Table 7: Cost Savings and Environmental Impacts per Plant

\begin{tabular}{lcccc}
\hline Sources of Impacts & $\begin{array}{c}\text { Cost Savings } \\
\$ \text { mil. }\end{array}$ & $\begin{array}{c}\mathrm{SO}_{2} \\
\text { mill. ton }\end{array}$ & $\begin{array}{c}\mathrm{NO}_{X} \\
\text { mil. ton }\end{array}$ & $\begin{array}{c}\mathrm{CO}_{2} \\
\text { mil. ton }\end{array}$ \\
\hline From Heat Rate & 1.20 & 477 & 220 & 82,511 \\
From Coal Procurement & 6.87 & - & - & - \\
From Capacity Factor - Nuclear Replace & - & 1789 & 825 & 309,542 \\
From Capacity Factor - Nat. Gas Replace & - & 1775 & 591 & 153,326 \\
\hline & & & & \\
Combined Effect (Nuclear Replace) & 8.07 & 2,266 & 1045 & 392,053 \\
\% of Combined Effect & 14.7 & 7.55 & 7.55 & 7.55 \\
\hline Combined Effect (Nat. Gas Replace) & & & & \\
\% of Combined Effect & 8.07 & 2,252 & 811 & 235,837 \\
\hline
\end{tabular}

Note: "Heat Rate" results are based on parameter from Table 2, column 3. "Coal Procurement" results are based on estimates from Table 3, column 3. "Capacity Factor" results are based on estimates from Table 4, column 3. "Nuclear Replace" results assume nuclear plant generation replaces reduced coal generation. "Nat. Gas Replace" results assume natural gas plant generation replaces reduced coal generation. "\% of Combined Effect" refers to the percentage share of the average annual totals accounted for by the "Combined" results. 